Article

\title{
Strategies for Increasing the Productivity of Pulsed Laser Cladding of Hot-Crack Susceptible Nickel-Base Superalloy Inconel 738 LC
}

\author{
Christian Kästner®, Matthias Neugebauer, Klaus Schricker@ and Jean Pierre Bergmann * \\ Production Technology Group, Technische Universität Ilmenau, Gustav-Kirchhoff-Platz 2, \\ 98693 Ilmenau, Germany; christian.kaestner@tu-ilmenau.de (C.K.); matthias.neugebauer@tu-ilmenau.de (M.N.); \\ klaus.schricker@tu-ilmenau.de (K.S.) \\ * Correspondence: jeanpierre.bergmann@tu-ilmenau.de; Tel.: +49-3677-69-2981
}

Received: 17 August 2020; Accepted: 28 August 2020; Published: 29 August 2020

check for updates

\begin{abstract}
A novel repair strategy based on decoupled heat source for increasing the productivity of wire-assisted pulsed laser cladding of the $\gamma^{\prime}$-precipitation strengthening nickel-base superalloys Inconel 738 low carbon (IN 738 LC, base material) and Haynes 282 (HS 282, filler material) is presented. The laser beam welding process is supported by the hot-wire technology. The additional energy is utilized to increase the deposition rate of the filler material by increasing feeding rates and well-defining the thermal management in the welding zone. The simultaneous application of laser pulse modulation allows the precise control of the temperature gradients to minimize the hot-crack formation. Accompanying investigations such as high-speed recordings and numerical simulations allow a generalized statement on the influence of the adapted heat management on the resulting weld seam geometry (dilution, aspect ratio and wetting angle) as well as the formation of hot-cracks and lack of fusion between base and filler material. Statistical analysis of the data-the input parameters like laser pulse energy, pulse shape, hot-wire power and wire-feeding rate in conjunction with the objectives like dilution, aspect ratio, wetting angle and hot-cracking behavior-revealed regression functions to predict certain weld seam properties and hence the required input parameters.
\end{abstract}

Keywords: nickel-base superalloy; repair welding; hot-wire; pulse shaping; heat management; statistical analysis; numerical simulation; hot-cracks

\section{Introduction}

Nickel-base superalloys are the preferential material for stator and rotor blades in stationary gas turbines (commonly IN 738 LC) due to their outstanding high temperature, creep and fatigue strength as well as toughness, impact resistance and resistance to hot gas corrosion, especially since they retain their strength up to $90 \%$ of their melting temperature [1,2]. Due to the particularly high material and manufacturing costs, there is a significant economic interest in the repair or overhaul instead of the replacement of operationally stressed components [3]. Laser cladding has developed as a suitable repair strategy [4-6]. Laser powder cladding is economically preferred for the repair of large-area damages due to the high deposition rates, e.g., at the leading edge of the turbine blade [7]. However, it is not possible to process filigree repairs at the blade tip or for superficial defects on the shovel blade. Thereby, pulsed laser beam welding offers advantages for these applications in terms of low material loss (avoidance of spatters compared to powder processes) and unnecessary preheating, since hot-cracking can be minimized by pulse shaping. The conditional weldability of $\gamma^{\prime}$-precipitation strengthening nickel-base superalloys at room temperature requires special technical efforts to avoid or minimize hot-cracking in the heat-affected zone and in the base material as well as distortion and residual 
stresses if similar $\gamma^{\prime}$-precipitation strengthening filler materials are to be applied. By application of sequential laser pulses of approximately 1 to $50 \mathrm{~ms}$ pulse duration at frequencies of 1 to $25 \mathrm{~Hz}$, the melt pool may solidify in the pulse breaks, and dendritic growth and microsegregation may be reduced $[8,9]$. Hence the latent heat of sequential melting and solidification is beneficial for preventing strains in the welding zone [9]. Furthermore, a transient influence on the melt pool temperature can be achieved by pulse shaping, which in turn results in a direct intervention in the solidification rate and the temperature gradients. Thus, the resulting stress gradients can be transformed into crack-free or low-crack regimes [8-10]. Due to the limited productivity, i.e., the low application rate or wire melting deposition rate, the process has so far only been implemented industrially for repairing individual damage of blades. The setting of a local material-specific temperature-time regime and the simultaneous increase in productivity are subject to economic and technological limits. On the one hand, low melting deposition rates result from the required frequency or pulse overlap. On the other hand, there is an opposing behavior of the resulting dilution and wetting angle. This is contradictory for multilayer surface repair welding, where both dilution and wetting angle have to be minimized to realize large beads with defect-free fusion. Thus, despite fully utilized pulse energy or average power of a laser beam source, the melting deposition rate cannot be further increased.

If it is possible to specifically extract heat quantities from the pulsed laser beam welding process and transfer them to the filler material, it might be feasible to increase the deposition rate and welding speed while maintaining or reducing the dilution of the base material. The advantages of the pulsed process and the temperature-time-regime are maintained. An approach to decouple heat sources is, for example, in the filler material by the hot-wire technology [11,12]. The hot-wire temperature should not exceed the softening or plasticizing temperature of the filler material, i.e., larger than $900{ }^{\circ} \mathrm{C}$ in case of HS 282, to guarantee a stable wire-feed. The situation is schematically summarized in Figure 1.
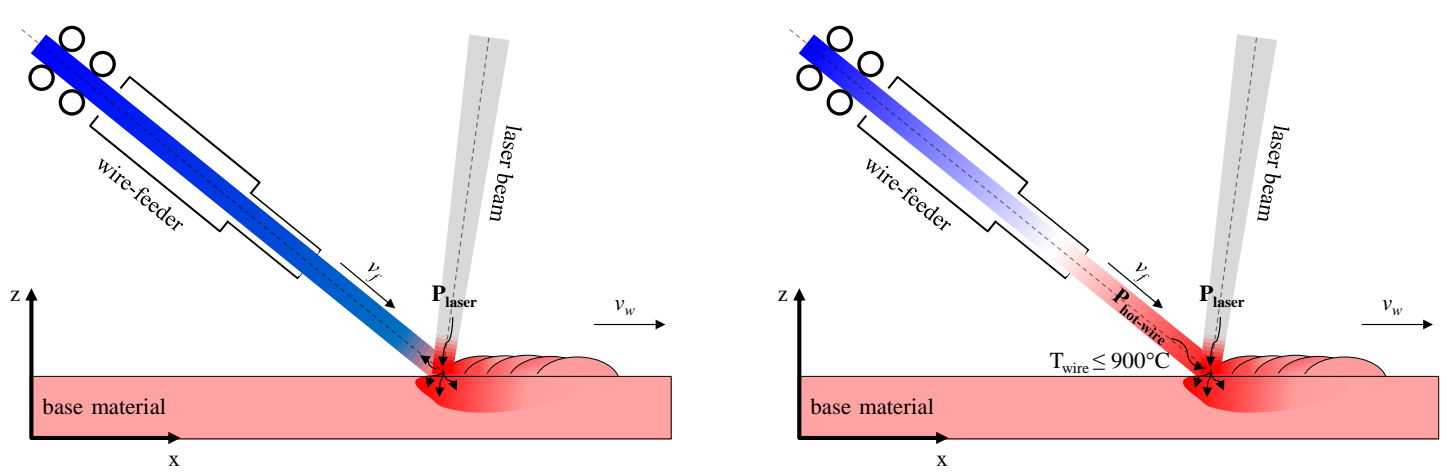

Figure 1. Strategies for decoupling of heat sources: use of conventional (left) and hot-wire technology (right).

In this study, the influence of the hot-wire technology is investigated next to the laser pulse energy, the pulse shape and the wire-feeding rate onto the geometrical weld seam properties as well as the hot-crack formation. To conclude about the correlations of each individual parameter and combinations of them on the weld seam and the hot-cracking tendency, a statistical analysis of about 400 parameter combinations was pursued. Thus, information about reliability and predictability of the welding process are revealed. Numerical simulation of the thermal management completed the study.

\section{Materials and Methods}

\subsection{Materials}

One base material was investigated: IN $738 \mathrm{LC}$ as plates with a dimension of $107 \times 104 \times 5 \mathrm{~mm}^{3}$. The filler material was HS 282 with a wire diameter $d_{w}$ of $400 \mu \mathrm{m}$. The base material was solution 
annealed, and polished and cleaned with isopropyl in advance of the welding process. The chemical compositions of materials are shown in Tables 1 and 2.

Table 1. Chemical composition of IN 738 LC in weight percent [13].

\begin{tabular}{lccccccccccccccc}
\hline & Ni & Cr & Co & Al & Ti & W & Mo & Ta & Nb & Si & C & B & Fe & Mn & S \\
\hline $\min$ & bal. & 15.7 & 3.0 & 3.2 & 3.2 & 2.4 & 1.5 & 1.5 & 0.6 & 0 & 0.09 & 0.003 & 0 & 0 & 0 \\
$\max$ & & 16.3 & 9.0 & 3.7 & 3.7 & 2.8 & 2.0 & 2.0 & 1.1 & 0.3 & 0.13 & 0.08 & 0.05 & 0.02 & 0.015 \\
\hline
\end{tabular}

Table 2. Chemical composition of HS 282 in weight percent [14].

\begin{tabular}{cccccccccccc}
\hline & Ni & Cr & Co & Mo & Ti & Al & Fe & Mn & Si & C & B \\
\hline $\min$ & 57 & - & - & - & - & - & 0 & 0 & 0 & - & - \\
$\max$ & bal. & 20.0 & 10.0 & 8.5 & 2.1 & 1.5 & 1.5 & 0.3 & 0.15 & 0.06 & 0.005 \\
\hline
\end{tabular}

\subsection{Experimental Setup and General Aspects}

The laser beam source was a Yb: YAG fiber laser (IPG 450/4500-QCW-MM-AC) with $200 \mu \mathrm{m}$ fiber guide and laser optics (IPG FLW D30). The focus diameter was $470 \mu \mathrm{m}$. Welding was performed with a perpendicular incidence angle of $10^{\circ}$. Wire feeding was supported by a wire-feeder Elmotec DVS 1490 at an angle of $20^{\circ}$ relative to the substrate. The shielding inert-gas flow was supplied with argon 4.6 at an angle of incidence of $40^{\circ}$ relative to the substrate and a flow rate of $10 \mathrm{~L} / \mathrm{min}$. The parameters of the setup are based on corresponding preliminary investigations $[15,16]$. The entire control of the whole setup was carried out by a CNC 3-axis portal system ILZ Ilmenau Laserportal.

The welding speed was kept constant at $1.8 \mathrm{~mm} / \mathrm{s}$. Lower welding speeds were not taken into account from the point of view of high productivity. Higher welding speeds were technically not feasible due to the limited average power of the laser beam source of $450 \mathrm{~W}$. The wire-feeding rate was varied to $4 \mathrm{~mm} / \mathrm{s}, 8 \mathrm{~mm} / \mathrm{s}, 12 \mathrm{~mm} / \mathrm{s}$ and $16 \mathrm{~mm} / \mathrm{s}$, so that the ratio of welding speed to wire feeding rate $v_{w} / v_{f}$ was $0.45,0.22,0.17$ and 0.11 , respectively. The pulse frequency was set to $14 \mathrm{~Hz}$.

A schematic of the instrumentational setup is depicted in Figure 2. Further instrumentation was high-speed recording to image the melting deposition process. Further descriptions follow in the subsections.

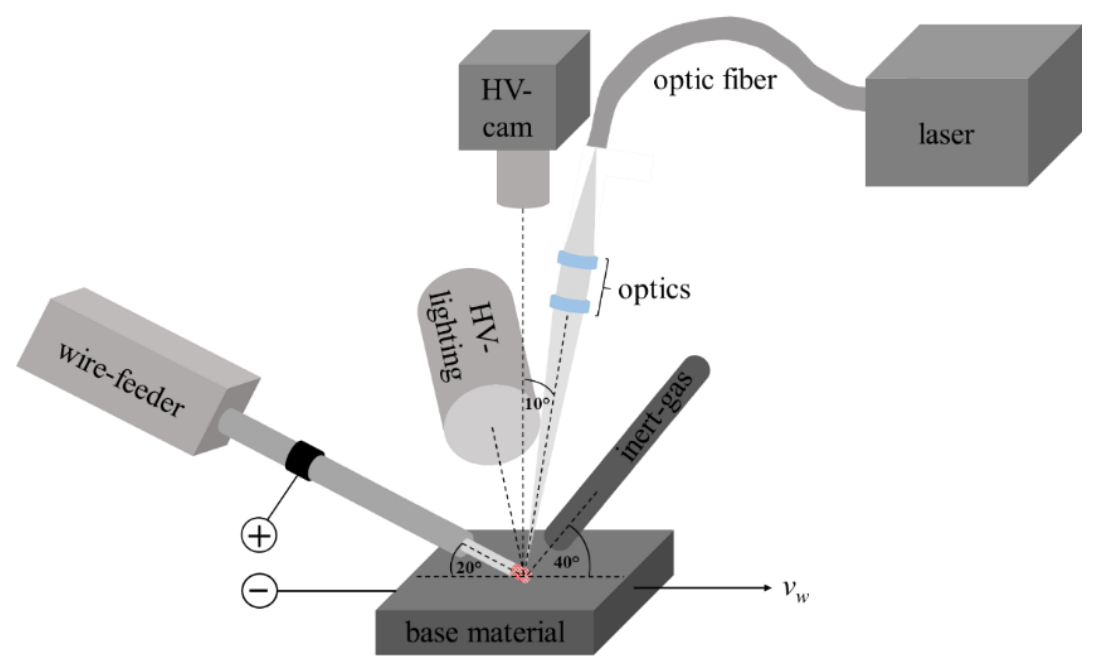

Figure 2. Schematic representation of the experimental setup. 


\subsection{Decoupling of Heat Source-Hot-Wire Technology}

Electrical resistance heating of the filler material was achieved by applying a constant current between the substrate (cathode) and the wire-feeding lance (anode). The maximum hot-wire power of $P_{h w}^{\max }=12 \mathrm{~W}$ was chosen that the temperature of the wire tip was about $900{ }^{\circ} \mathrm{C}$ to retain a certain stiffness for stable filler support to the welding zone. The maximum hot-wire capacity may appear low, but is explained by the small diameter of the filler wire $(400 \mu \mathrm{m}$, see Section 2.1). The temperature and corresponding heating power were determined in a previous experiment with a pyrocam Optris 3MH1-SF. The influence of the hot-wire power $P_{h w}$ on the welding processing was investigated in equidistant steps to the maximum hot-wire power $P_{h w}^{\max }$, i.e., for $100 \%(12 \mathrm{~W}), 70 \%(8 \mathrm{~W}), 40 \%(5 \mathrm{~W})$ and $0 \%(0 \mathrm{~W})$. Since the electrical power is deposited in the complete wire between the electrical contacts with a length of about $15 \mathrm{~mm}$, only an effective heating zone to the welding process of just the wire tip with a length of about $400 \mu \mathrm{m}$ is to be considered. The $400 \mu \mathrm{m}$ tip length is conceptional since the tip diameter is also $400 \mu \mathrm{m}$ and hence the active melting zone of the wire is just about this volume to be considered. That means, that only the ratio of the effective tip length to the bare wire length, $l_{\text {tip }} / l_{\text {bare }}=$ 0.027 , times the applied electrical power contributes to the melting process. Together with the feeding rate to welding speed ratio $v_{f} / v_{w}$, i.e., in total the volume fraction, the effective heating power can be calculated by:

$$
P_{h w}^{e f f}=\frac{l_{\text {tip }}}{l_{\text {bare }}} \frac{v_{f}}{v_{w}} P_{h w}
$$

The resulted effective hot-wire powers for applied wire-feeding rates and applied electrical hot-wire powers are shown in Table 3. Besides the applied electrical hot-wire power also the corresponding temperatures for the steady state, i.e., without wire-feeding, is shown in Table 3. It is to note here, that indeed the effective hot-wire powers are low, but due to the small material volume comparably large heating temperatures up to $900^{\circ} \mathrm{C}$ are achieved.

Table 3. Effective hot-wire powers for the applied wire-feeding rates and hot-wire powers.

\begin{tabular}{ccccc}
\hline \multirow{2}{*}{$\begin{array}{c}\text { Wire-Feeding Rate } \\
{[\mathbf{m m} / \mathrm{s}]}\end{array}$} & $0 \% \boldsymbol{P}_{h w}^{\max }\left(2{ }^{\circ} \mathbf{C}\right)$ & $40 \% \boldsymbol{P}_{h w}^{\max }\left(550{ }^{\circ} \mathbf{C}\right)$ & $\mathbf{7 0} \% \boldsymbol{P}_{h w}^{\max }\left(\mathbf{7 4 0}{ }^{\circ} \mathbf{C}\right)$ & $\mathbf{1 0 0 \%} \boldsymbol{P}_{h w}^{\max }\left(\mathbf{9 0 0}{ }^{\circ} \mathbf{C}\right)$ \\
\hline 4 & 0.00 & 0.28 & 0.50 & 0.71 \\
8 & 0.00 & 0.57 & 1.00 & 1.42 \\
12 & 0.00 & 0.85 & 1.50 & 2.13 \\
16 & 0.00 & 1.14 & 2.00 & 2.84 \\
\hline
\end{tabular}

\subsection{Pulse Shaping}

In general, ramp-down pulse shapes are commonly used for industrial applications with respect to the possibility to form crack-free weld seams [17]. Such a pulse shape has already been proven to be advantageous for minimizing hot-cracking of $\gamma^{\prime}$-precipitation strengthening IN 738 LC in earlier investigations $[15,16,18]$. The pulse shaping was carried out as shown in Figure 3. The temporal course of the laser beam power was measured by means of Coherent PowerMax Pro. Depicted are the applied pulse shapes (solid line) and the actual pulse shapes (dashed lines). The deviation of the actual pulse shape from the applied pulse shape is due to the power threshold of the laser beam source, which does not allow continuous ramp-down to zero. The pulse plateau was always $50 \%$ of the pulse peak power. The peak length and the power down ramps were set to $5 \mathrm{~ms}$, respectively. The plateau lengths were varied accordingly in three steps to $10 \mathrm{~ms}$ (pulse shape 1), $20 \mathrm{~ms}$ (pulse shape 2), and $30 \mathrm{~ms}$ (pulse shape 3), respectively. The pulse peak was applied to deposit sufficient laser pulse energy to melt on the filler and base material and, together with the subsequent plateau, to maintain the melt pool and deposit further filler material at reduced heat input. The plateau lengths and the power ramps at the end of the pulse were applied to control the up-heating and down-cooling gradients, respectively, and hence the hot-cracking behavior of the materials. The applied peak powers ranged from 400 to $1300 \mathrm{~W}$. The resulting pulse energies, applied in the experiments, are also shown in Figure 3. The cross-marked 
cells were not applicable due to the limited average power of the laser beam source. The comparison of the pulse energy and the pulse shape makes it easier to conclude about the influence of the pulse shape at a given pulse energy to the hot-cracking behavior.

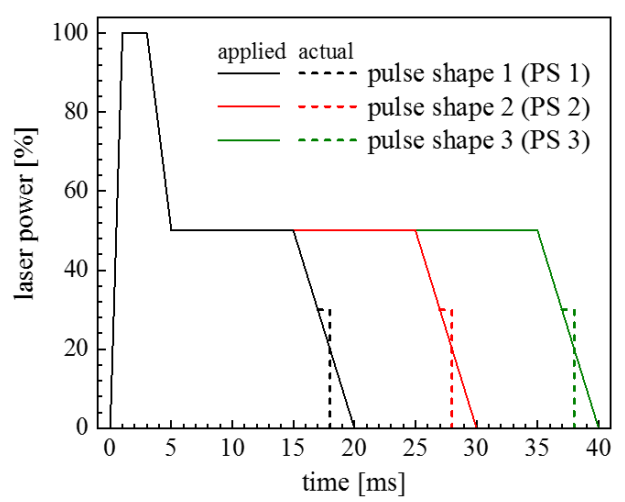

\begin{tabular}{cccc}
\hline Peak Power & \multicolumn{3}{c}{ Pulse Energy [J] } \\
[W] & PS 1 & PS 2 & PS 3 \\
\hline 400 & 4.1 & 9.1 & 14.1 \\
500 & 5.1 & 10.1 & 15.1 \\
600 & 6.2 & 11.2 & 16.2 \\
700 & 7.2 & 12.2 & 17.2 \\
800 & 8.2 & 13.2 & 18.2 \\
900 & 9.2 & 14.2 & 19.2 \\
1000 & 10.3 & 15.3 & $\times$ \\
1100 & 11.3 & 16.3 & $\times$ \\
1200 & 12.3 & 17.3 & $\times$ \\
1300 & 13.3 & 18.3 & $\times$ \\
\hline
\end{tabular}

Figure 3. Schematic representation of the applied and actual pulse shapes (left) and summary of the applied laser peak powers and corresponding pulse energies for the different actual pulse shapes (right).

The comparison of the pulse energy and the pulse shape makes it easier to conclude about the influence of the pulse shape at a given pulse energy to the geometrical weld seam properties and the hot-cracking behavior.

\subsection{High-Speed Recording}

High-speed recordings were taken with a Photron SA-X2 at $3000 \mathrm{~Hz}$ in vertical direction to the substrate. The camera was equipped with a blocking filter to the surrounding light and laser radiation, but transparent to the HV-illumination laser system (Cavitar CaviLux) at $808 \mathrm{~nm}$ wavelength. The illumination system had no specific orientation, adjusted for maximum contrast of the camera image.

\subsection{Temperature-Dependent Emissivity of IN 738 LC}

The emissivity curve of the base material was experimentally determined by heating an IN 738 LC sample with a defocused diode laser (Laserline LDM 1.000-30) at various laser powers and measuring the temperatures, once with a Type-K thermocouple (Peak Tech 5110), placed in a borehole from underneath $1 \mathrm{~mm}$ below the heated surface, and once with a pyrometer (Kleiber KGO 840-LO) on the surface. Thus, the pyrometer was adjusted to the temperature of the thermocouple by tuning the emissivity coefficient. At the moment of measurement, the temperature was stable due to the long heating times of about 15 to $30 \mathrm{~min}$. This also ensured that the temperatures at the thermocouple and at the pyroscope were comparable. The emissivity curve of IN 738 LC is shown in Figure 4 as function of the temperature. This result is in accordance with Ref. [19,20]. The emissivity curve was also claimed for HS 282 in the numerical simulation. 

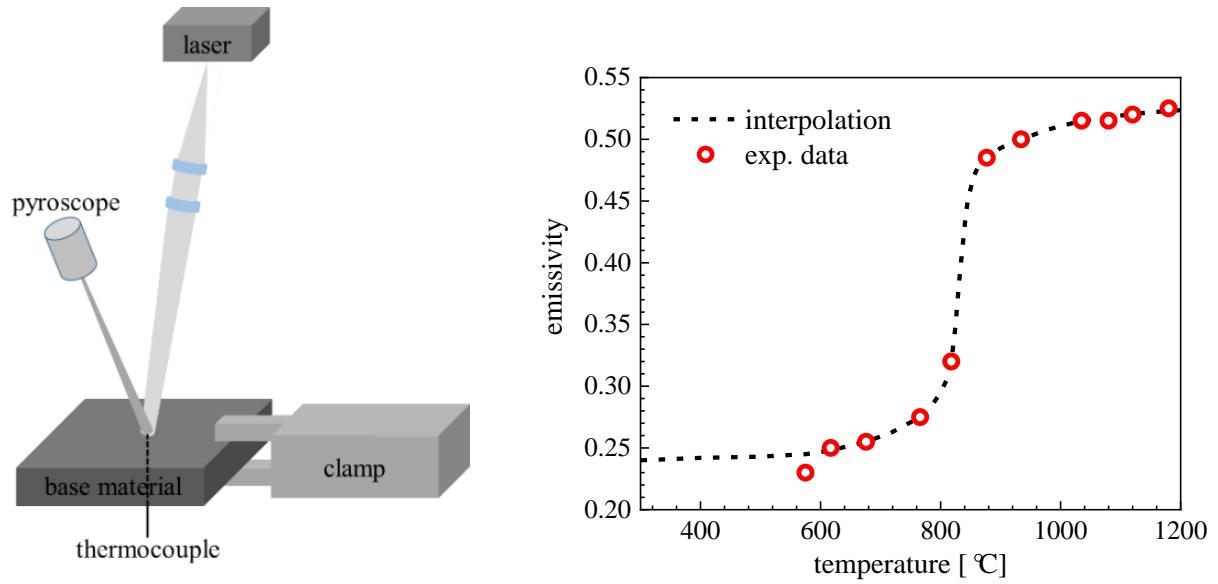

Figure 4. Temperature-dependent emissivity: measurement setup (left) and emissivity curve of IN 738 LC (right).

\subsection{Numerical Simulation}

Numerical simulations were carried out with COMSOL Multiphysics. The transient thermal modelling contained heat dissipation, radiation, free and forced convection as well as phase transition. The laser intensity distribution was claimed to be Gaussian and the photon energy was deposited by absorption. The laser beam focus of $470 \mu \mathrm{m}$ diameter was set to the surface of the base material. The temperature-dependent absorption coefficient of the base and filler material was modelled by the experimentally conducted emissivity, according to Kirchhoff's law for thermal equilibrium [21]. The hot-wire heating power deposited to the welding process was taken from the considerations above. To include the phase transition, the solidus and liquidus temperatures were taken from Ref. [22]. The residual material data was taken from the COMSOL materials data base of IN 718, due to its similarity to IN $738 \mathrm{LC}$, and upgraded with the experimentally found emissivity. The welding zone was covered with a shielding inert-gas flow of $10 \mathrm{~L} / \mathrm{min}$, modelled by forced thermal convection. The remaining area was modelled by free thermal convection. Additionally, thermal radiation was claimed for the complete top surface of the base material. For simplification, the weld seam was assumed to be completely deposited just from the beginning and half-cross-sectional buried into the base material with a cylindrical shape, whereas the diameter was parametrized by the wire-feeding rate, that the deposited filler volume was equal to the weld seam volume. The meshing was denser in the welding zone than in the rest of the base material. Figure 5 summarizes the applied conditions of the simulation model.

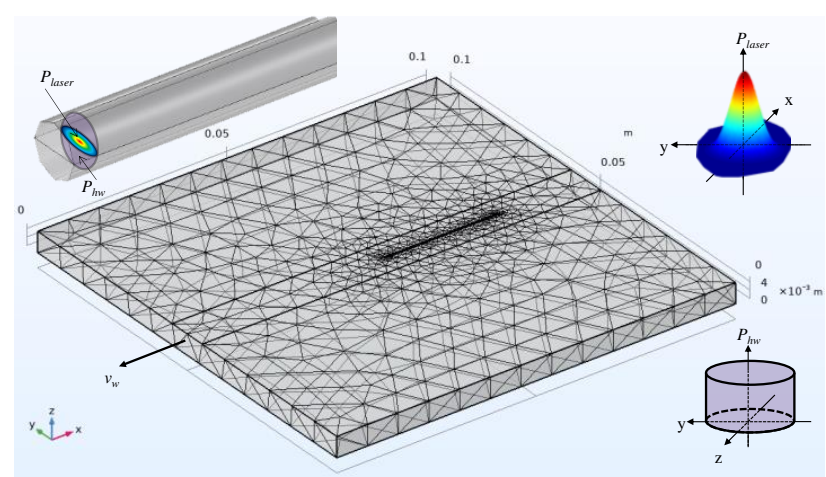

Figure 5. Schematic representation of the applied simulation conditions: meshing, weld seam geometry, heating power and laser power distribution. 
The numerical model was validated by comparison of a numerically conducted temperature curve (average line temperature at top face of the weld seam at the accidental point of the laser beam) and a pyroscope measurement $(0.5 \mathrm{~mm}$ measurement point at the accidental point of the laser beam) during the welding process under same welding conditions. Figure 6 shows the comparison of numerically and experimentally conducted results in form of transient temperature curves during one laser pulse of $1000 \mathrm{~W}$ peak power and $1 \mathrm{~mm} / \mathrm{s}$ wire-feeding rate, with and without $12 \mathrm{~W}$ hot-wire power at room temperature. The pulse shape is also given for comparison. Both numerical and experimental graphs indicate the transient power distribution of the pulse shape: (1) the temperature peak at the beginning belongs to the pulse peak, (2) a heating during the pulse plateau and (3) cooling at the power ramp down followed by a less progressive cooling during the pulse break. It is to note here, that both experiment and simulation reflect the impact of the hot-wire on the processing temperature during welding.

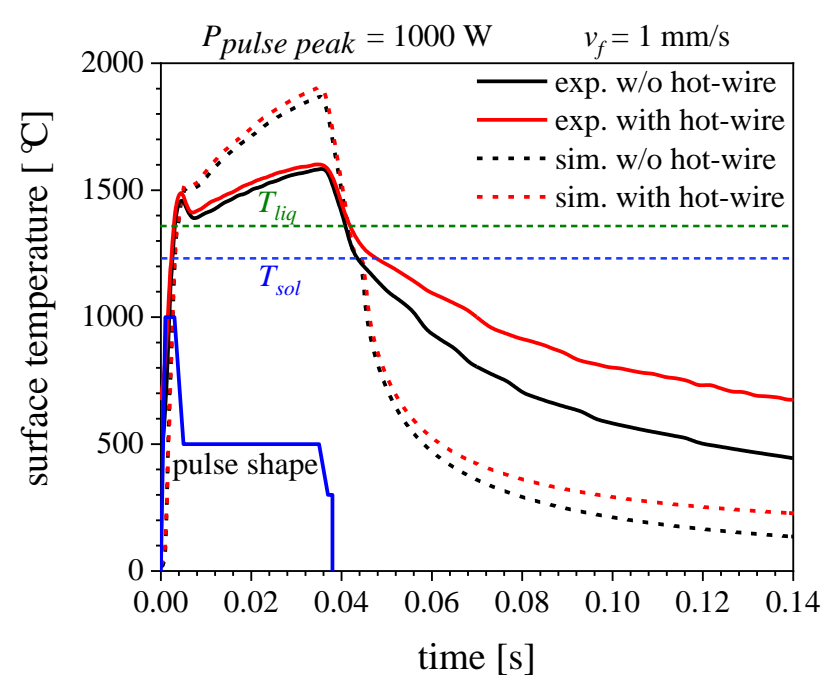

Figure 6. Comparison of numerical and experimental transient temperature curves.

The deviations between numerical and experimental result may be due to the simplified numerical model and the temperature data acquisition of the pyroscope. The pyroscope measurement was realized with a static emissivity coefficient, whereas the simulation was performed with the experimentally conducted emissivity curve. Furthermore, the measurement point of the pyroscope was different to the weld seam width and averaged the temperature of the whole area. The temperature measurement in the simulation was solely undertaken at the weld seam surface. Another reason may also be a misalignment of the pyroscope measurement point and/or the filler-wire due to oscillations of the setup during the experiment. The deviation between experiment and simulation implies, that the numerical model may not be suitable for quantitative analysis of the welding process. Nonetheless, it is suitable to draw qualitative conclusions about the impact of the input parameters on the thermal management during the welding process and is hence a useful tool.

\subsection{Metallography}

The manufactured weld seams were examined by means of metallographic microsections with regard to lack of fusion, hot-cracking, seam geometry, i.e., dilution $D$, wetting angle $\Theta$ and aspect ratio $A$, and deposition efficiency $\varphi$ and deposition rate $R_{d} . A_{D}$ is the area of dilution and $A_{H}$ the area of the buildup, $H$ the height and $W$ the width of the buildup, $D_{P}$ the penetration depth and $A_{w}$ the cross-sectional area of the filler wire, compare Figure 7 [23]. 


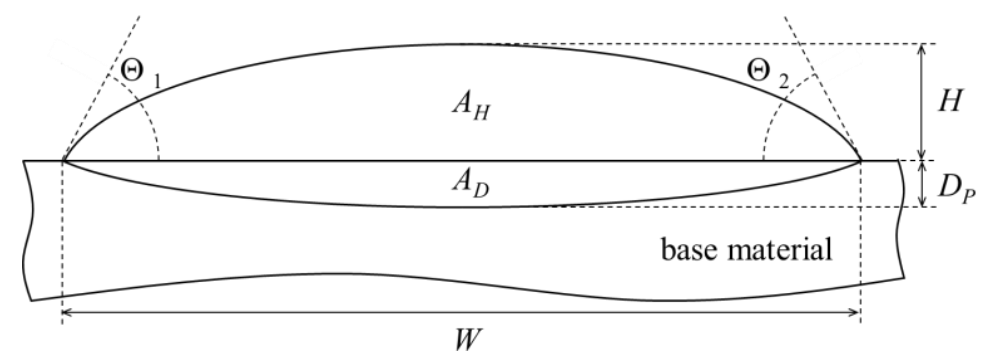

Figure 7. Geometric quantities for characterization of the weld seam.

$$
\begin{gathered}
D=\frac{A_{D}}{A_{H}+A_{D}} \\
A=\frac{H}{W} \\
\Theta=\frac{\Theta_{1}+\Theta_{2}}{2} \\
\varphi=\frac{A_{H}}{A_{w}} \\
R_{d}=\frac{1}{4} \rho_{H S 282} A_{w} v_{w}=3.74 \cdot \varphi \cdot\left[\frac{g}{h}\right]
\end{gathered}
$$

Crack-free welds were determined according to the user criteria for crack lengths smaller than $10 \mu \mathrm{m}$. For this purpose, four samples per weld seam were separated by wire erosion (Charmilles Robofil 240) and embedded into epoxy resin using a hot-mounting press (Buehler SimpliMet XPS1). The grinded/polished and etched ( $3 \mathrm{~s}$ with Kalling No. 2) specimens were analyzed with a light microscope ZEISS AxioScope.A1 (AxioVisio SE64 software).

\subsection{Statistical Analysis}

Statistical analysis was pursued with commercial software package Minitab ${ }^{\circledR}$, aiming on the extraction of correlation functions between the input parameters-pulse energy, pulse shape, hot-wire power and wire-feeding rate-and the objectives-dilution, aspect ratio, wetting angle and hot-crack formation [24]. The generation and optimization of the regression functions bases on the Anderson-Darling statistics $[24,25]$. To improve the significance for strongly scattering data and to generate a normal distributed data set, a Box-Cox transformation of data was performed before analysis [26,27]. Therefore, about 1600 micrographs, i.e., four samples of each of the 400 parameter sets, of weld seams were characterized with respect to the geometry (dilution, aspect ratio and wetting angle) and hot-cracking state.

\subsection{Summary of Main Parameters}

Table 4 briefly summarized the main parameters investigated in this study as well as the static welding and processing conditions during the investigations. 
Table 4. Investigated parameters and further welding and monitoring conditions.

\begin{tabular}{cc}
\hline Parameter & Range/Values \\
\hline effective hot-wire power & $0-2.84 \mathrm{~W}$ \\
laser pulse energy & $4.1-19.2 \mathrm{~J}$ \\
laser pulse peak power & $400-1300 \mathrm{~W}$ \\
number of pulse shapes & 3 \\
laser pulse frequency & $14 \mathrm{~Hz}$ \\
weld velocity & $1.8 \mathrm{~mm} / \mathrm{s}$ \\
wire-feeding rate & $1-16 \mathrm{~mm} / \mathrm{s}$ \\
HV-recording & $3000 \mathrm{kHz}$ \\
pyrometer sampling & $100 \mathrm{kHz}$ \\
pyrometer averaging & $10 \mathrm{samples}$ \\
\hline
\end{tabular}

\section{Results and Discussion}

\subsection{Preliminary Investigation}

In a previous study [13], the setup was applied just for a wire-feeding rate of $2 \mathrm{~mm} / \mathrm{s}$ to gather first information about the welding conditions. The investigated parameter range of 400 to $1200 \mathrm{~W}$ pulse peak power provided the processing window for the main test after qualitative analysis of the welding processes with regard to lack of fusion, hot-crack, pore and spatter formation, see Figure 8.
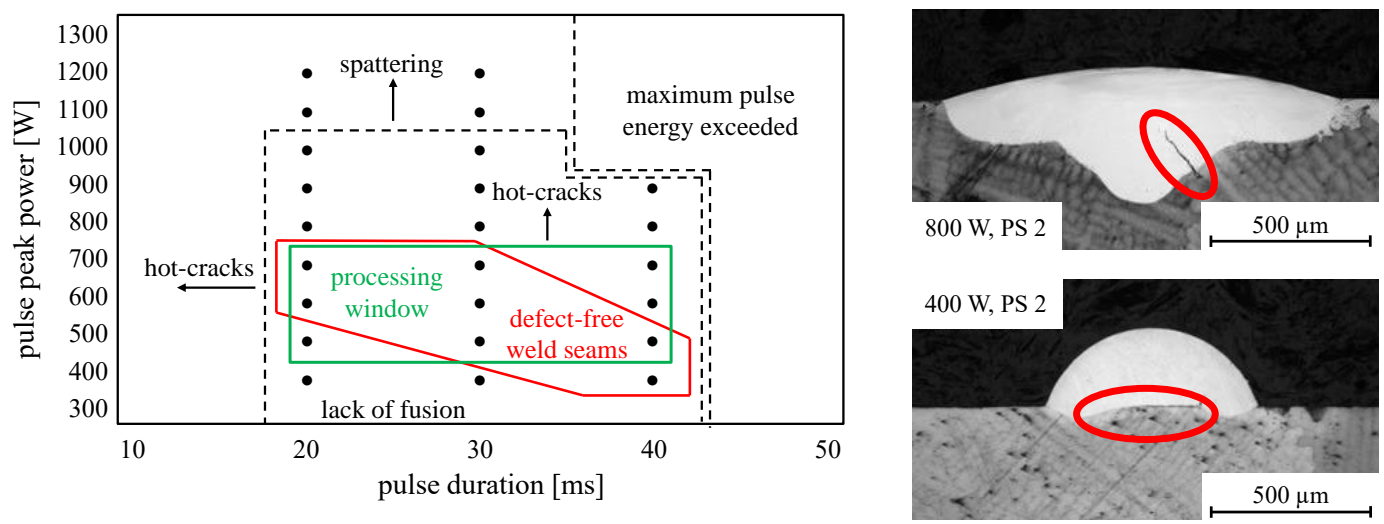

Figure 8. Processing window and its limitations (left) and typical welding defects (right): hot-crack (top panel) and lack of fusion (bottom panel). The wire-feeding rate was always $2 \mathrm{~mm} / \mathrm{s}$ and the pulse frequency $14 \mathrm{~Hz}$.

The micrographs on the right side of Figure 8 exemplarily demonstrate some limitations of the investigated parameter space. While lack of fusion occurred at $400 \mathrm{~W}$ pulse peak powers and lower, pulse peak powers of $800 \mathrm{~W}$ and higher lead to hot-cracks and from $1000 \mathrm{~W}$ also to spattering. In addition, the $800 \mathrm{~W}$ sample shows a clearly visible coupling of the laser beam and hence the associated penetration into the base material. This available power reserve of the laser beam source could thus potentially be used for melting further filler material and thus for increasing the productivity. The selection of the processing window (green) compared to the area of defect-free welds (red) is based on the assumption that the hot-wire technology actively intervenes in the temperature regime within the welding zone, so that the additional heat of the hot-wire can be substituted or added and consequently the formation of hot-cracks and lack of fusion may either be reduced or prevented. Figures 9 and 10 demonstrate how the pulse peak power and the pulse duration impact the weld seam geometry. Both cases, constant pulse duration and increasing pulse peak power as well as constant pulse peak power and increasing pulse duration, lead to larger pulse energy and hence to a larger heat deposition in the welding zone. This results in larger penetration depth, increasing width, but also decreasing 
buildup of the weld seam, whereas the influence of the pulse duration plays a lesser role than the pulse peak power.

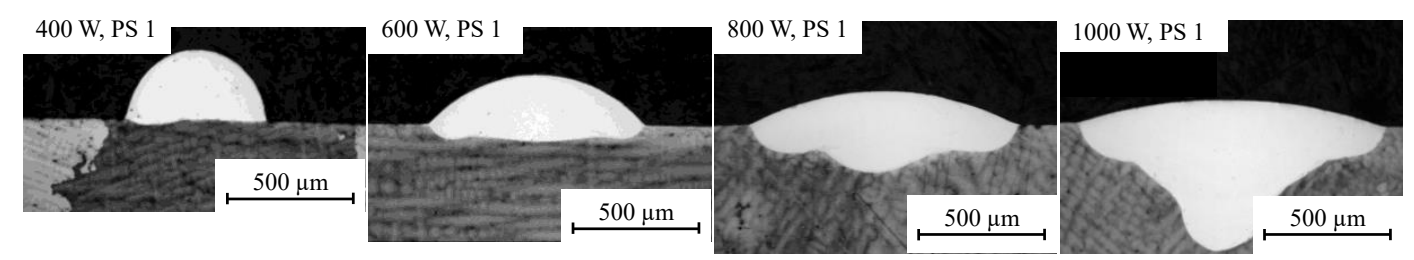

Figure 9. Weld seam geometry for varying pulse peak power and constant pulse duration. Wire-feeding rate was $2 \mathrm{~mm} / \mathrm{s}$ and pulse frequency $14 \mathrm{~Hz}$.
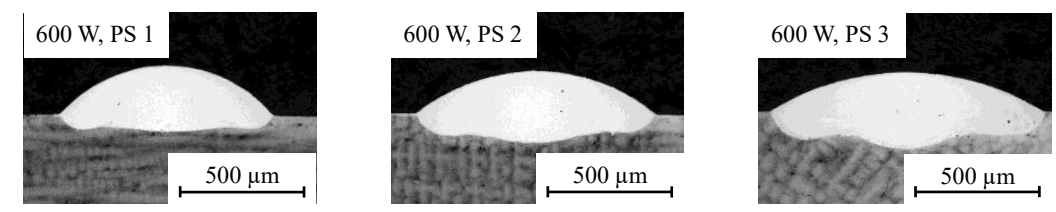

Figure 10. Weld seam geometry for varying pulse duration (PS 1, PS 2 and PS 3) and constant pulse peak power. Wire-feeding rate was $2 \mathrm{~mm} / \mathrm{s}$ and pulse frequency $14 \mathrm{~Hz}$.

The increasing penetration depth leads not only to a lower productivity, but also to larger temperature gradients in the base material and hence to a potentially increasing vulnerability to hot-cracks. On the other hand, too low a penetration depth may cause lack of fusion and, although the deposition rate is large, lead to unfavorable wetting angles for additive buildup in repair welding of larger areas and fill-ups. In terms of high productivity and defect-free repair welds, the pulse energy has to be chosen to yield preferably low dilution and low wetting angles, which seems to be contradictory, but may be achievable by subtle adjustment of the welding parameters. This circumstance will be addressed in the following as well as the aim to larger deposition rates.

\subsection{Influence of the Welding Parameters on the Weld Seam Geometry}

Based on the aforementioned preliminary results and argumentation, the processing window of the current study was shifted up to a pulse peak power range of 1000 to $1300 \mathrm{~W}$ since the additional laser power will be necessary to melt the additional filler material at larger wire-feeding rates of up to $16 \mathrm{~mm} / \mathrm{s}$. Furthermore, the pulse duration had to be reduced to $28 \mathrm{~ms}$ due to the limited average power of the laser beam source, which means that pulse shape 3 was no more applicable in this power range, compare Figure 2. Only one parameter set was conducted for pulse shape 3 at $900 \mathrm{~W}$ pulse peak power, which solely entered the statistical analysis, but is not discussed in detail. Thus, an intense study with about 400 parameter combinations was pursued. For better comparability of the data and its physically higher significance for description of the heat management in the welding zone, the pulse peak power is substituted to the pulse energy in the following study. Furthermore, dilution and wetting angle will be discussed in more detail than the aspect ratio due to their key function for additive repair welding.

Figure 11 depicts the dilution and wetting angle of the weld seams as function of pulse energy and hot-wire power for pulse shape 1 (18 ms pulse duration) and wire-feeding rates of 4,8 and $12 \mathrm{~mm} / \mathrm{s}$. Blue marked data points and corresponding micrographs belong to the lowest energy input (laser only), and red marked data points and corresponding micrographs belong to the highest energy input (laser and hot-wire). The wetting angle is represented by the color code of the surface plot. The data range of all diagrams is the same for better comparability. The data points represent the average values and their corresponding standard deviation of each four samples. 

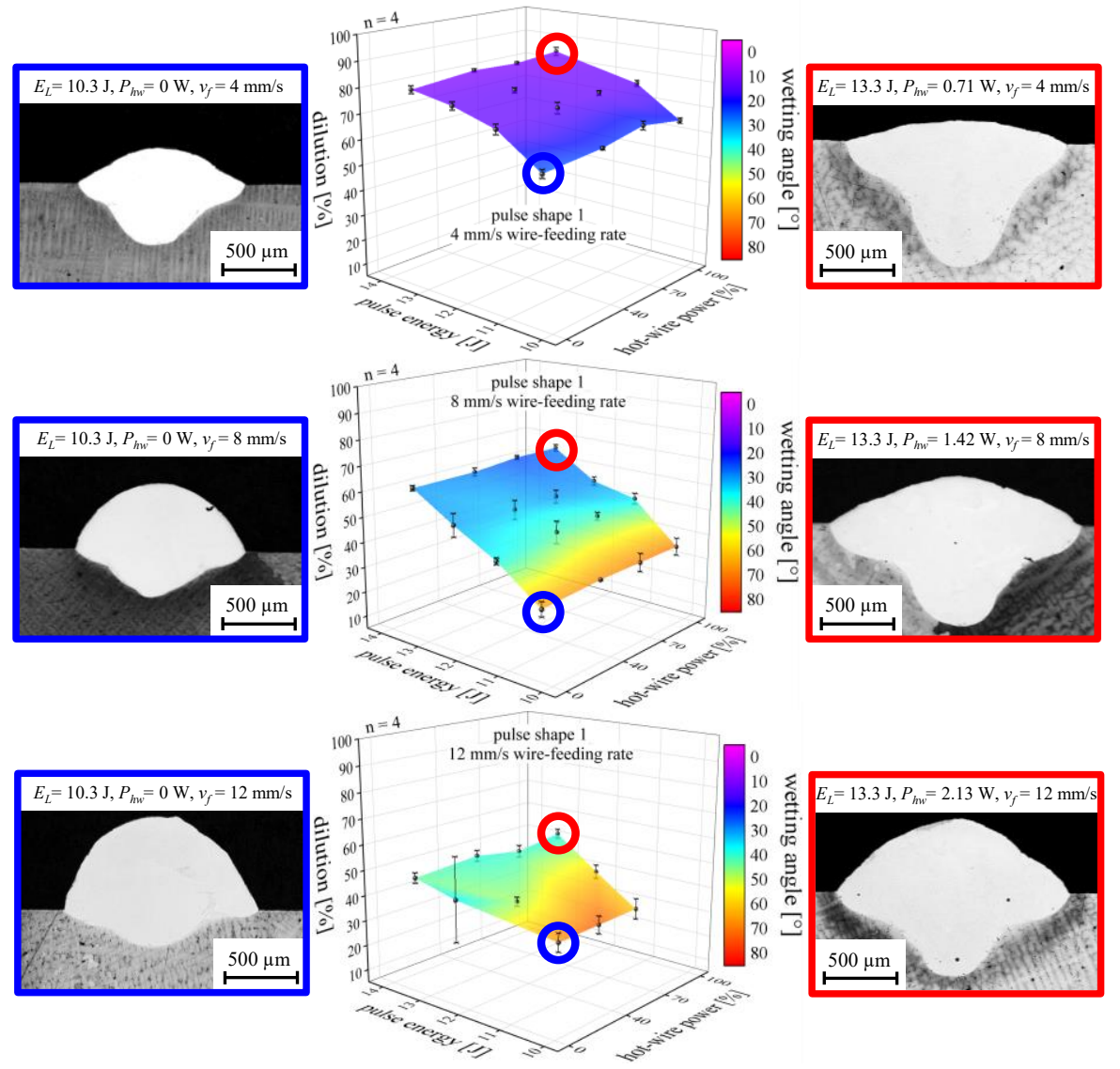

Figure 11. Dilution as function of pulse energy and hot-wire power for pulse shape 1 and wire- feeding rates of 4,8 and $12 \mathrm{~mm} / \mathrm{s}$. Blue marked data points and corresponding micrographs belong to the lowest energy input (laser only), and red marked data points and corresponding micrographs belong to the highest energy input (laser and hot-wire). The hot-wire power is given in percent in the diagrams and with absolute values in the header of the micrographs.

It is obvious, that an increasing pulse energy leads to larger dilution and smaller wetting angles, which is plausible since the pulse energy is the dominant heat source in the welding process. The hot-wire power is just the secondary heat source and hence plays a minor role-despite resulting temperatures of $900{ }^{\circ} \mathrm{C}$ at the wire tip. The variation of dilution and wetting angle is more or less heterodyned by fluctuations from sample to sample since the standard deviation of each data point is most likely larger than the variation of the average values of dilution and wetting angle for the different hot-wire powers at a given pulse energy. Figure 12 shows exemplarily the comparison of cross-sectional micrographs for different hot-wire powers and wire-feeding rates for pulse shape 1 and pulse energy of $13.3 \mathrm{~J}$. The minor impact of the hot-wire power on the weld seam geometry is obvious, whereas the wire-feeding rate dominantly controls the buildup efficiency. 


\begin{tabular}{|c|c|c|c|c|}
\hline \multirow{2}{*}{$\begin{array}{c}\text { feeding-rate } \\
{[\mathrm{mm} / \mathrm{s}]}\end{array}$} & \multicolumn{4}{|c|}{ hot-wire power [W] } \\
\hline & 0 & 5 & 8 & 12 \\
\hline 4 & & & & \\
\hline 8 & & & & \\
\hline 12 & & & & \\
\hline $1000 \mu \mathrm{m}$ & & & a & \\
\hline
\end{tabular}

Figure 12. Influence of the hot-wire power and the wire-feeding rate on the weld seam geometry.

This context becomes clearer by comparing the heat sources parameter range. The pulse energy varies from 10.3 to $13.3 \mathrm{~J}$, which compares to an average power of 144.2 to $186.2 \mathrm{~W}$ or pulse peak power of 1000 to $1300 \mathrm{~W}$, respectively, whereas the effective hot-wire power varies from 0 to $2.13 \mathrm{~W}$. Assuming an emissivity coefficient of about 0.5 of the melt (compare Figure 4), the effective laser power deposited as heat in the base and filler material still ranges from about 77 to $93 \mathrm{~W}$ in average and 500 to $650 \mathrm{~W}$ in peak, respectively. Thus, the heat input contributed by the hot-wire is in the range of $0 \%$ to $2.7 \%$. Hence the low effect of the hot-wire power is counterbalanced by statistical fluctuations during the welding process, whereas the laser beam power is large enough to seriously show an effect. Furthermore, it is clearly visible, that the standard deviations increase with increasing wire-feeding rate, which means, that the welding process becomes more and more instable as the wire-feeding rate increases. This may be a result of the continuous wire-feed, whereas the heat input by the laser beam is pulsed. During the pulse breaks the melt solidifies, but the wire-feeder is still conveying the filler. This may lead to mechanical stress of the wire, which releases when the welding zone re-melts and the wire is acceleratively pushed into the melt. Hence a quasi-pulsed wire-feeding is created, which also impacts the heat management of the welding process. The accelerated wire support leads to lower heat input in the base material and faster cooling down of the melt pool, which reduces the temperature gradients in the welding zone.

The wire-feeding rate is the dominant control parameter for dilution and wetting angle, next to the pulse energy. Increasing wire-feeding rates lead to decreasing dilution and increasing wetting angle at a given pulse energy, which is not astonishing since the larger amount of filler material absorbs most of the laser pulse energy and reduces the heat input into the base material. The effect of pulse energy and wire-feeding rate on the weld seam geometry is impressively demonstrated by the micrographs. The dilution becomes as lower and the wetting angle as larger as lower the pulse energy and as larger the wire-feeding rate become, i.e., larger melting deposition rates and lower temperature gradients in the welding zone can be gained. The comparison with micrographs of Figures 9 and 10, where the welding speed and wire-feeding rate was similar, reveals much higher weld seam quality at a lower feeding-rate of $2 \mathrm{~mm} / \mathrm{s}$.

The same study was performed also for larger pulse duration of $28 \mathrm{~ms}$, i.e., pulse shape 2 . Figure 13 depicts the dilution and wetting angle of the weld seams as function of pulse energy and hot-wire power for pulse shape 2 and wire-feeding rates of $4 \mathrm{~mm} / \mathrm{s}, 8 \mathrm{~mm} / \mathrm{s}, 12 \mathrm{~mm} / \mathrm{s}$ and $16 \mathrm{~mm} / \mathrm{s}$. Here, the same conclusions can be drawn as already found for pulse shape 1 . Hence it is more interesting to conclude about the effect of the pulse duration on the weld seam geometry. 

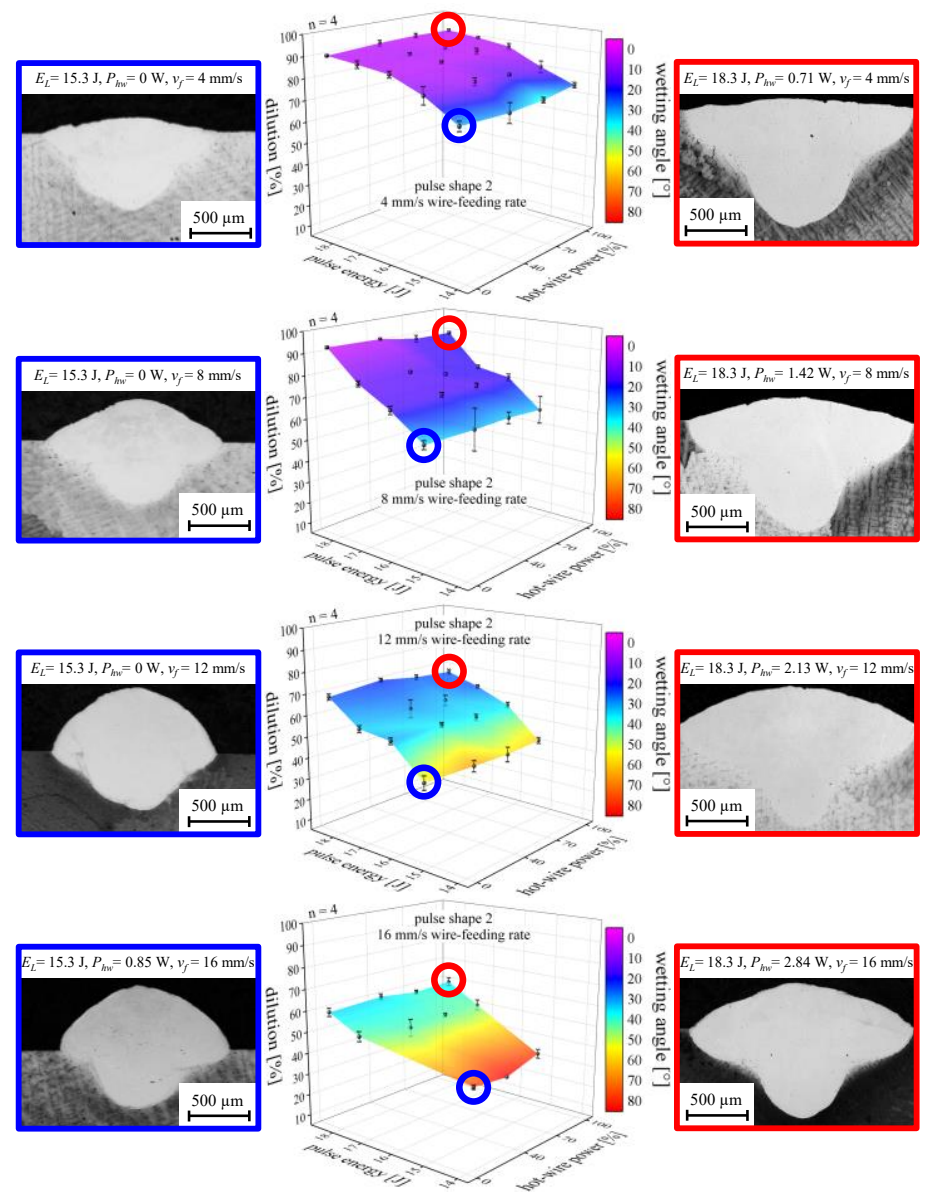

Figure 13. Dilution as function of pulse energy and hot-wire power for pulse shape 2 and wire-feeding rates of $4 \mathrm{~mm} / \mathrm{s}, 8 \mathrm{~mm} / \mathrm{s}, 12 \mathrm{~mm} / \mathrm{s}$ and $16 \mathrm{~mm} / \mathrm{s}$. Blue marked data points and corresponding micrographs belong to the lowest energy input (laser and hot-wire), and red marked data points and corresponding micrographs belong to the highest energy input (laser and hot-wire). The hot-wire power is given in percent in the diagrams and with absolute values in the header of the micrographs.

Whereas the pulse peak power range retained in this experiment at 1000 to $1300 \mathrm{~W}$, the pulse energy and average laser beam power range increased to 15.3 to $18.3 \mathrm{~J}$ and 214.2 to $256.2 \mathrm{~W}$, respectively, due to the increased pulse duration. The larger pulse energy allowed also a larger wire-feeding rate of $16 \mathrm{~mm} / \mathrm{s}$. Hence the global range of the effective hot-wire power increased to $2.84 \mathrm{~W}$. Thus, the contribution of the hot-wire to the total heat input changed to a range of $0 \%$ to $2.6 \%$ under the assumption of an emissivity coefficient of about 0.5 . The reader is again referred to the experimental section for more detailed information about the effective hot-wire power values of each parameter set. The increased pulse energy, due to the increased pulse duration, lead to an overall larger dilution and smaller wetting angle compared to pulse shape 1 .

The hot-wire power shows again no significant impact on the weld seam geometry, as reflected in Figure 14. 


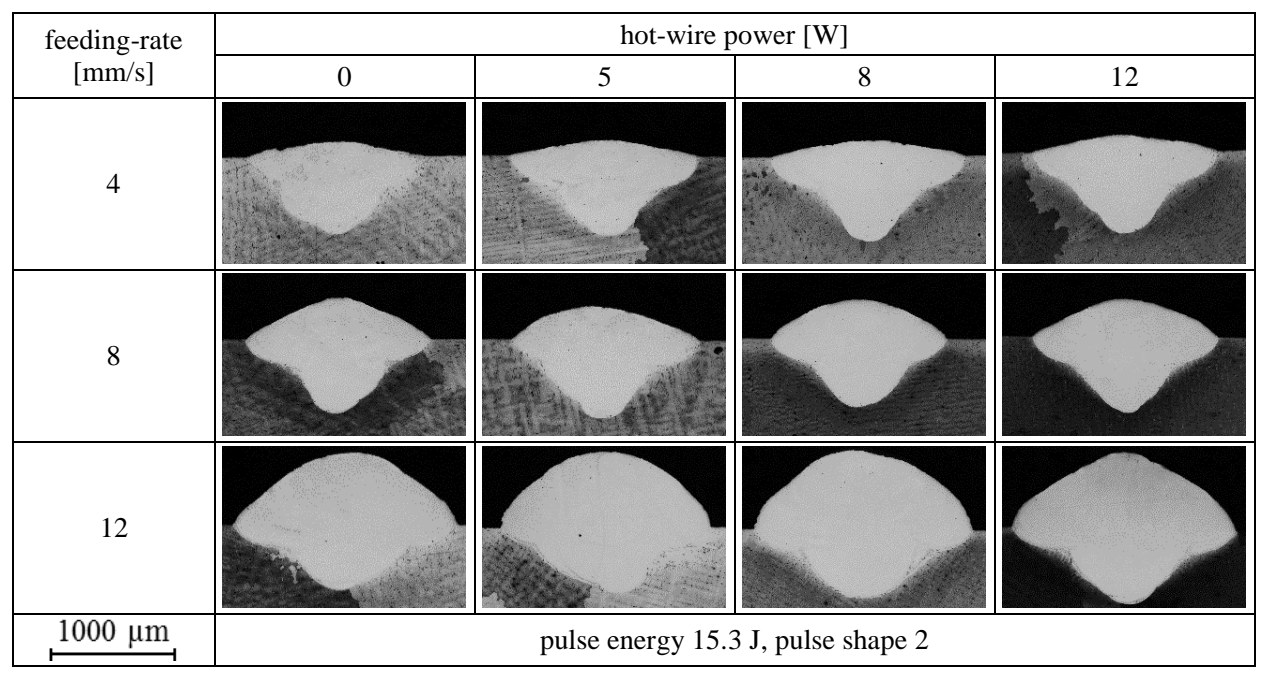

Figure 14. Influence of the hot-wire power and the wire-feeding rate on the weld seam geometry.

Since the hot-wire power has no remarkable effect on the weld seam geometry, all data were averaged over the applied hot-wire power to gain more clarity of the effect of the main input parameters pulse energy, pulse shape and wire-feeding rate, by combining all data in one diagram for each objective, i.e., dilution, wetting angle and aspect ratio. Figure 15 depicts the hot-wire power averaged objectives as function of the pulse energy for all wire-feeding rates and pulse shapes. The error bars represent the combined standard deviation (geometric mean) of the average value and the single standard deviations of each hot-wire power. Hence the combined standard deviation becomes larger than the largest single standard deviation of one data set. The results of Figure 15 are straight forward. The dilution increases continuously with the pulse energy and decreases continuously with the wire-feeding rate. Wetting angle and aspect ratio show an opposite trend. Interestingly, the curves of both pulse shapes do not continue each other on the pulse energy scale for the same wire-feeding rate. This implies, that also the transient power distribution of the laser beam pulse has an impact on the objectives. For example, the dilution values for pulse shape 2 at about 15.3 and $16.3 \mathrm{~J}$ are the same as for pulse shape 1 at about 12.3 and $13.3 \mathrm{~J}$, respectively. The curves of pulse shape 1 seem to be shifted by about $3 \mathrm{~J}$ towards lower energies. This means, that similar objectives can be achieved at significant lower pulse energy just by changing the pulse shape to a shorter plateau length. The larger pulse peak and plateau power, respectively, which are necessary to achieve the same pulse energy at lower pulse duration, lead to larger heat input from the beginning of the laser pulse and a stronger coupling into the base material, respectively, and hence to a larger dilution. On the other hand, the same pulse peak and plateau power at lower pulse duration leads to a similar heat input and coupling into the base material at the beginning. Thus, a prolonged pulse duration keeps the melt pool open for a longer time, which increases the heat penetration into the base material, but also allows the deposition of more filler material. 

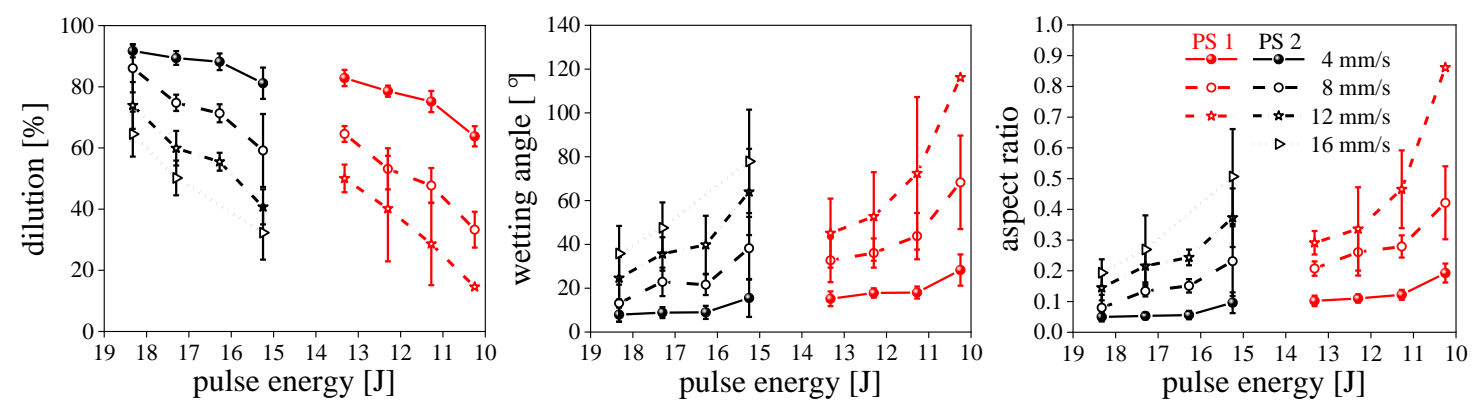

Figure 15. Hot-wire power averaged objectives as function of the pulse energy for the applied wire-feeding rates and pulse shapes (PS). The legend of aspect ratio is general for all objectives.

Finally, both effects are counterbalancing, that an intermediate parameter set leads to the same dilution as well as wetting angle and aspect ratio for different pulse durations. Comparing Figure 2, pulse shape 1 facilitates low pulse energy of $13.3 \mathrm{~J}$, but $1300 \mathrm{~W}$ pulse peak power achieves similar objectives of pulse shape 2 with $16.3 \mathrm{~J}$, but only $1100 \mathrm{~W}$ pulse peak power. Furthermore, the wire-feeding rate also allows similar considerations. Low pulse energy and low wire-feeding rate lead to similar objectives for larger pulse energy and larger wire-feeding rate. However, it is also important to mention here, that indeed the objectives are similar, the dimension of the weld seam or the absolute deposition of the filler material may significantly differ; compare micrographs in Figures 11 and 13.

The aforementioned example makes it clear, that although the parameters dilution, wetting angle and aspect ratio can be kept constant by selecting suitable parameters, the seam geometry still changes. For example, a higher wire-feeding rate in conjunction with a higher pulse energy provides the same dilution, but the actual material application or the absolute seam geometry may change significantly. Furthermore, it can be assumed that similar weld seam geometries with significantly different temperature-time profiles can be generated in the base material through a smart selection of the processing parameters. The influence on the deposition rate, i.e., the productivity, is discussed as follows.

\subsection{Productivity Enhancement}

The currently achieved deposition efficiencies and rates, again averaged over all hot-wire powers for clarity, are shown in Figure 16a,b, respectively. Furthermore, also the productivity enhancement factor was also calculated for the different wire-feeding rates in comparison to the initial wire-feeding rate of $4 \mathrm{~mm} / \mathrm{s}$, once as function of the pulse energy (c) and once averaged of the pulse energy as function of the wire-feeding rate (d). It is obvious, that the deposition efficiency and the productivity increased continuously with the wire-feeding rate, e.g., comparing the smallest and largest wire-feeding rate for pulse shape 2, a four-fold wire-feeding rate lead to an about five-fold deposition efficiency since less laser power is deposited in the base material, which is also reflected by the lower dilution, compare Figure 15. This correlation can also be identified for decreasing pulse energy at a distinct wire-feeding rate, but with a much lower intensity. Hence the main factor controlling the productivity is indeed the wire-feeding rate, whereas the pulse energy for a distinct pulse shape and the hot-wire power have only subordinated impact. Nonetheless, the deposition rate could be increased from about $4 \mathrm{~g} / \mathrm{h}$ to about $20 \mathrm{~g} / \mathrm{h}$. 

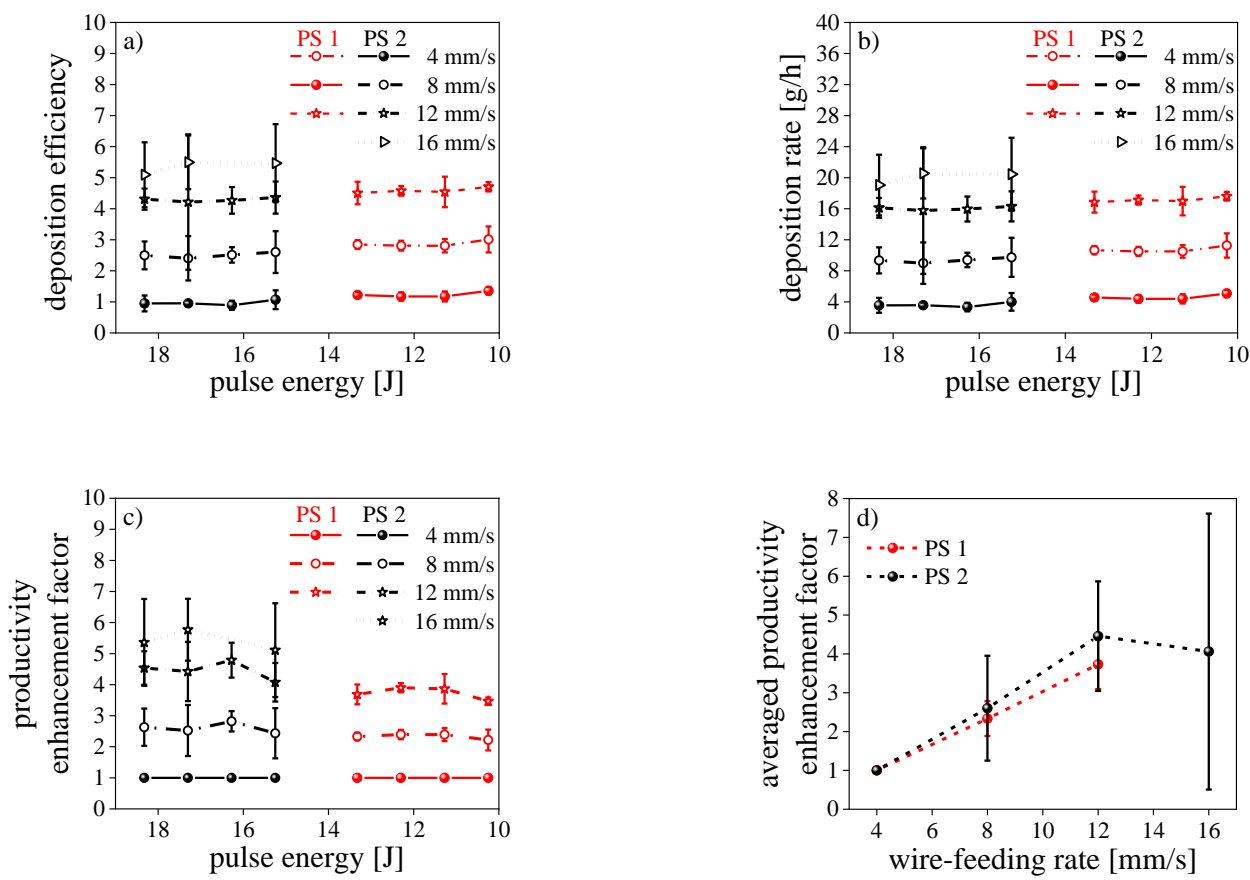

Figure 16. Hot-wire power averaged deposition efficiency (a) and rate (b) as well as the productivity enhancement factor (c) as function of pulse energy for the applied wire-feeding rates and pulse shapes (PS) and the pulse energy averaged productivity enhancement factor (d) as function of wire-feeding rate.

\subsection{Statistical Analysis of the Weld Seam Geometry}

To gain deeper insight into the relationship between the objectives and the predictor variables, i.e., the input parameters, a statistical analysis of the whole data set was conducted. The regression functions were calculated for each objective and allowed a statistical optimization of the input parameters to yield objective sets with certain weighting of each objective for individual purpose. One has to note here, that the pulse shape entered the regressions in terms of the plateau length of the laser pulse, which is the sole differentiating factor between the different pulse shapes. All input parameters entered linearly and partially bifactorial, i.e., square of one parameter or product of two parameters, into the regression function after Box-Cox transformation. Not all bifactorial terms were taken into account to reduce the multicollinearity between the predictor variables and increase the significance. The strength of influence of each input parameter in the regression function is represented by the Pareto chart. Figure 17 depicts the Pareto charts for the best-fit regression functions of dilution, wetting angle and aspect ratio. The abscissa of the Pareto chart represents the standard effect of each input parameter and combinations of them on the individual objectives, i.e., the intensity how the different input parameters enter the regression functions. The ordinate shows the input parameters and combinations of them, sorted by intensity from top to bottom.
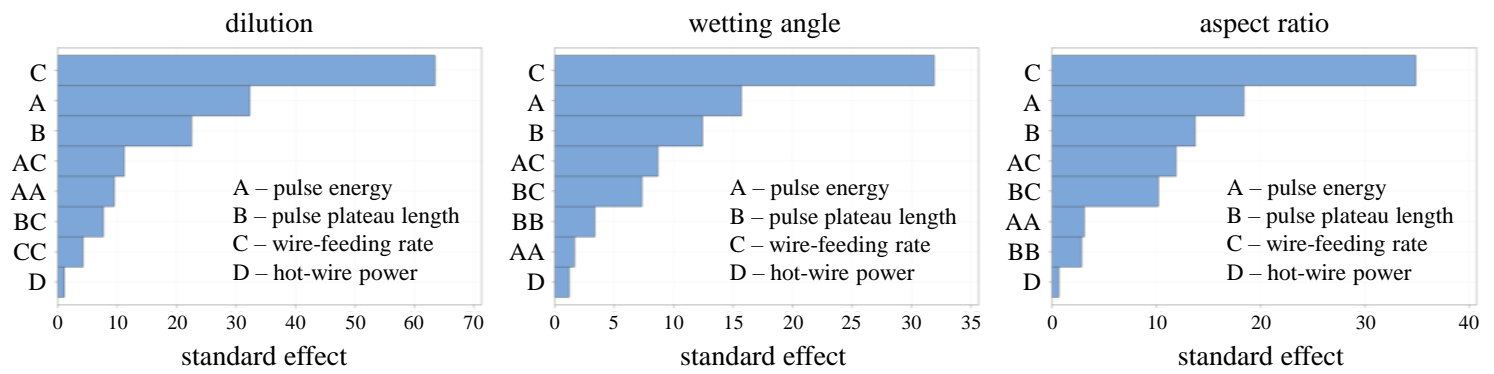

Figure 17. Pareto charts for the best-fit regression functions. 
The Pareto charts reveal the strongest influence of the wire-feeding rate for all objectives. The influence of the pulse energy and the pulse shape is reduced whereas the hot-wire power is subordinate. The functional correlation between the input parameters and the objectives is represented by the main effects diagram in Figure 18, which depicts more clearly the findings from the Pareto charts. The steepness of the graphs represents the intensity of impact. The wetting angle and the aspect ratio show nearly the same functional dependency of the individual input parameters. The dilution reveals a roughly inverted correlation with the input parameters in comparison to the wetting angle and the aspect ratio, respectively. Similar results could already be obtained with another laser beam source and similar pulse shapes, but different ramp-down times for constant pulse length [28].

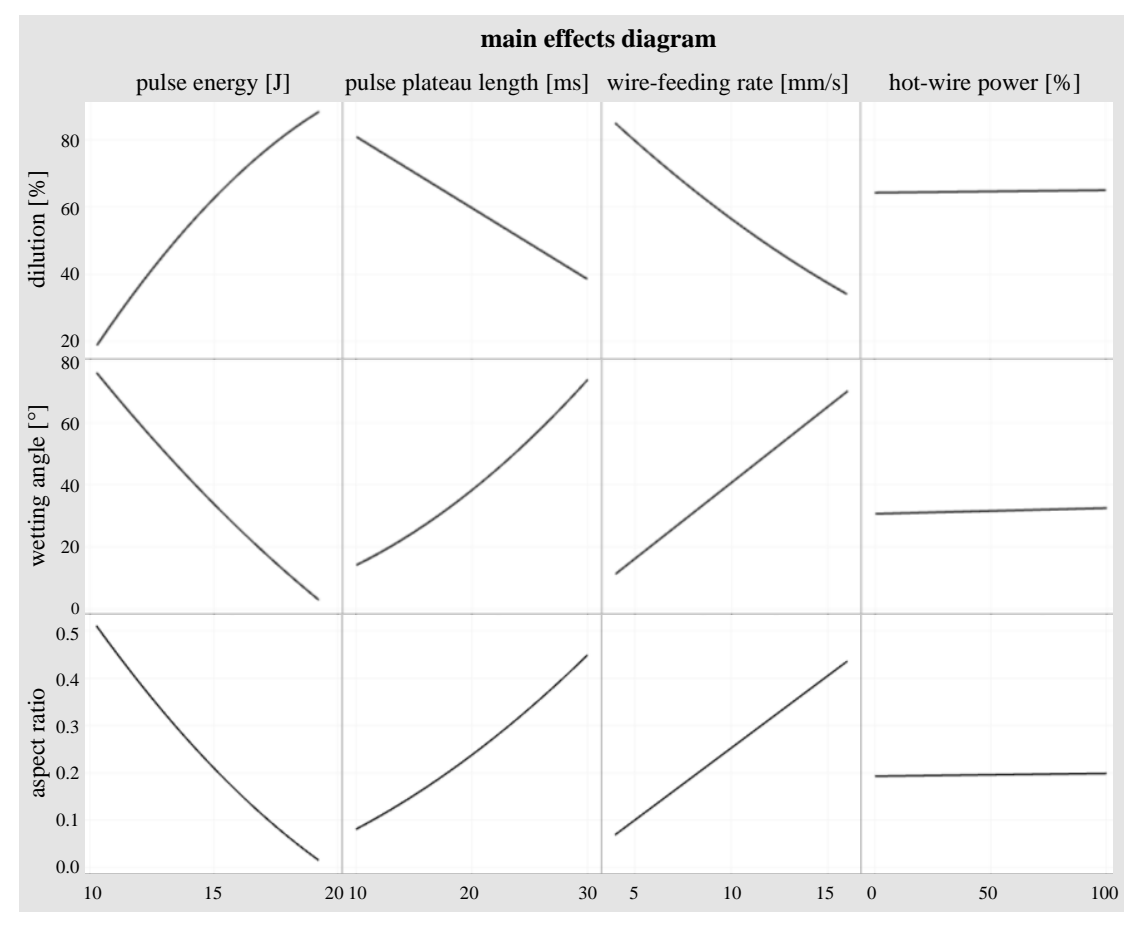

Figure 18. Main effects diagram representing the correlation between objectives and predictor variables.

\subsection{Investigation of the Thermal Management in the Welding Zone}

\subsubsection{Bulk Solidification Time}

Besides the impact of the input parameters on the weld seam geometry and the productivity, also the influence on the heat management is also of certain interest, especially concerning the hot-cracking susceptibility. Information about the thermal management could experimentally be concluded from the solidification times, conducted from the high-speed recordings of the welding process. The analysis of the recordings revealed no complete solidification during one periodic time $(71.4 \mathrm{~ms} @ 14 \mathrm{~Hz}$ pulse frequency) for pulse shape 1 at higher pulse energy and pulse shape 2 at all investigated pulse energies, i.e., the surface of the melt pool did not completely solidify during the pulse breaks. Figure 19 shows the comparison of pulse shape 1 and 2 for lowest energy input in this study. It is evident that the melt pool does not completely solidify for pulse shape 2 at least for lowest energy input. 
PS 1

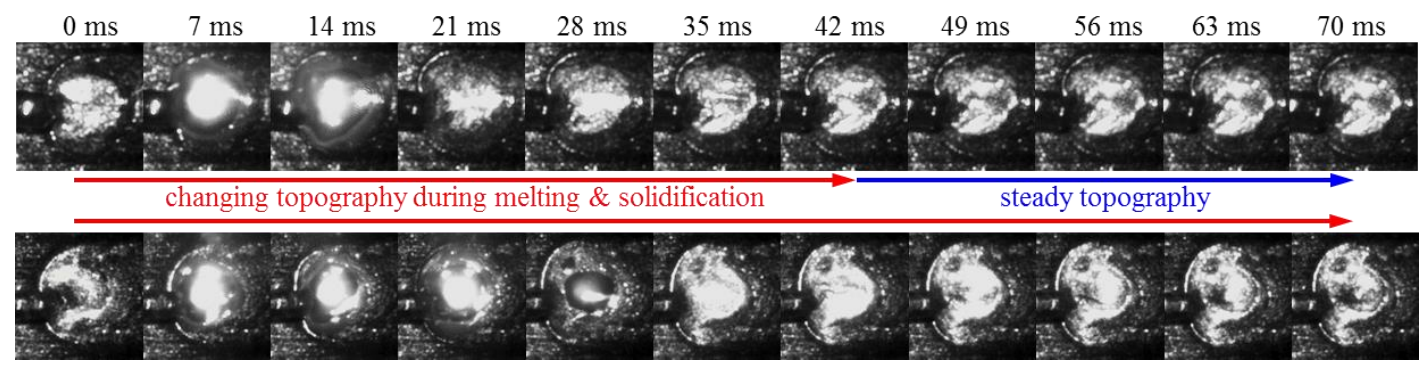

Figure 19. Melting and solidification process for pulse shape 1 and 2 during one periodic time, both for $1000 \mathrm{~W}$ pulse peak power, $4 \mathrm{~mm} / \mathrm{s}$ wire-feeding rate and without hot-wire application.

Thus, for general description, a bulk solidification time is defined by that time lapse from the end of the laser pulse until no further filler could be set into the welding zone due to a solidification of deeper regions inside the melt pool. Hence the effect of the wire-feeding rate on the bulk solidification time was conducted by averaging over the applied hot-wire powers (in percentage) for each pulse shape and pulse energy (Figure 20 left). The linear fits (dashed lines) just visualize the general trend. In principle, the bulk solidification time increases continuously with the wire-feeding rate for all pulse shapes and pulse energies (indicated in the diagram with the applied pulse peak power). This is explained by the low thermal conductivity of nickel-base superalloys. The larger wire-feeding rate leads to a larger deposition of the filler material, which provokes a heat accumulation, keeping the melt pool molten for a longer time. Furthermore, the effect is increased for longer pulse durations (PS 2), indicated by the larger steepness of the dashed lines for pulse shape 2, but a different pulse energy.
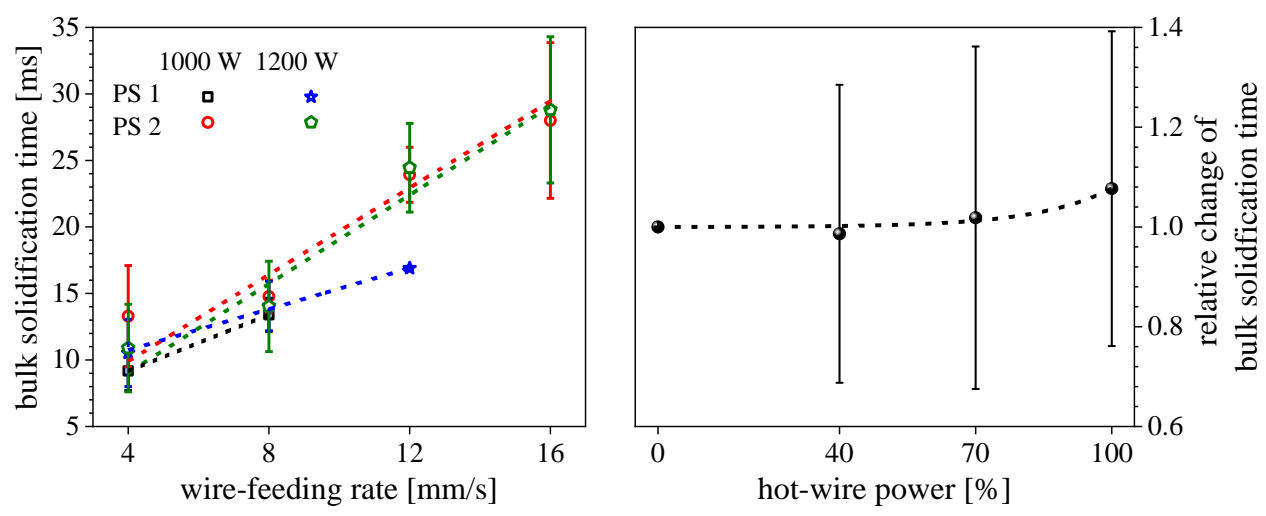

Figure 20. Bulk solidification time as function of the wire-feeding rate, averaged over all hot-wire powers (left), and relative change of the bulk solidification time as function of the hot-wire power, averaged over all pulse shapes, pulse energies and wire-feeding rates (right).

Due to the small effect of the hot-wire power and the apparently arbitrary scattering of the bulk solidification times, only the relative change of the bulk solidification time $\Delta \tau$ was identified by averaging over all pulse peak powers (index $i$ and $N_{1}=2$ ), pulse shapes (index $j$ and $N_{2}=2$ ) and wire-feeding rates (index $k$ and $N_{3}=4$ ) to illustrate the general effect of the hot-wire power by the following Equations (7)-(9). The change of the bulk solidification time relative to the initial value without hot-wire, i.e., $P_{h w}=P_{0}$, as function of the applied hot-wire power is shown in Figure 20 on the righthand side. Data were acquired according to Equations (7)-(9). The exponential fit (dashed line) just visualizes the general trend. In fact, a small impact of the hot-wire power is observed. A mean relative change to longer solidification times is achieved with increasing hot-wire power.

$$
\Delta \tau\left(P_{h w}\right)=\overline{\tau\left(P_{h w}\right)} \pm \delta \tau\left(P_{h w}\right)
$$




$$
\begin{gathered}
\overline{\tau\left(P_{h w}\right)}=\frac{1}{N_{1} N_{2} N_{3}} \sum_{k=1}^{N_{3}} \sum_{j=1}^{N_{2}} \sum_{i=1}^{N_{1}} \frac{\tau\left(P_{0}\right)-\tau_{i, j, k}\left(P_{h w}\right)}{\tau\left(P_{0}\right)} \\
\delta \tau\left(P_{h w}\right)=\sqrt{\frac{1}{N_{1} N_{2} N_{3}\left(N_{1} N_{2} N_{3}-1\right)} \sum_{k=1}^{N_{3}} \sum_{j=1}^{N_{2}} \sum_{i=1}^{N_{1}}\left(\frac{\tau\left(P_{0}\right)-\tau_{i, j, k}\left(P_{h w}\right)}{\tau\left(P_{0}\right)}-\overline{\tau\left(P_{h w}\right)}\right)^{2}}
\end{gathered}
$$

Nonetheless, the error bars are very large as a result of the roughly scattering data, implying a very low and most likely less systematic effect. The scattering most likely results from the discontinuous wire-feeding due to the periodic melting and solidification. Hence the hot-wire power is heterodyned by much stronger effects and may be neglected as a significant factor for the thermal management in contrast to the wire-feeding rate, pulse shape and pulse energy.

\subsubsection{Thermal Modelling}

Furthermore, the thermal management of the welding process was investigated by numerical simulations. The solely thermal modelling was allowed to retrace the impact of the input parameters on the temperature field in the base and filler material. Figure 21 shows the transient average bulk temperature of the welding zone during one periodic time. The diagrams, representing the influence of the pulse peak power and the hot-wire power, also illustrate the influence of the pulse shape. It is obvious, that the pulse peak power has the strongest influence on the temperature. The temperature is increasing with increasing pulse peak power during the laser pulse, which also leads to an increased temperature of the cooling curve, when the laser pulse is finished. The hot-wire power has just a minor effect as already concluded from the experimental results. The temperature of the cooling curve is just slightly increased with increasing hot-wire power (compare the magnified range of the cooling curve). No effect is observed during the laser pulse due to the low energy input compared to the laser beam. Otherwise, the wire-feeding rate shows most likely only an effect during the laser pulse (compare the magnified range of the pulse plateau), but not on the cooling curve. The temperature continuously increases with the wire-feeding rate. Again, the larger wire-feeding rate leads to an increased deposition of the filler material, which provokes a heat accumulation and hence an increasing temperature. Due to the elevated temperature in the base material during the welding process and the much larger volume of hot bulk, i.e., base material and already deposited filler, compared to the continuously supported hot-wire tip, the hot-wire power may be neglected.

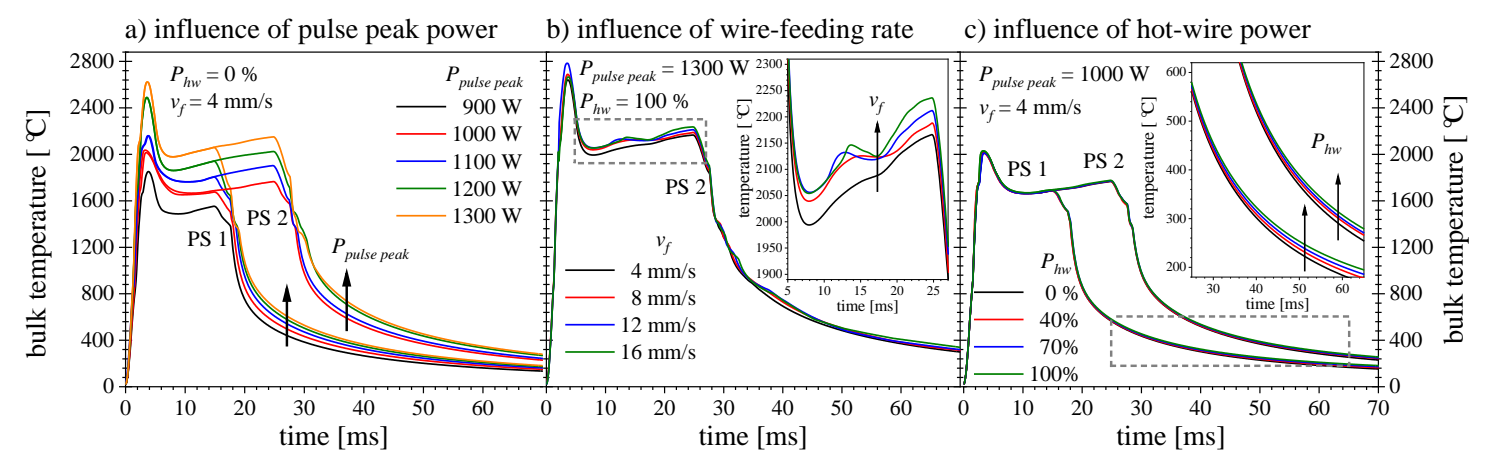

Figure 21. Bulk temperature-profiles from numerical simulations of one laser pulse for various parameter settings: influence of the (a) pulse peak power $P_{\text {pulse peak, }}(\mathbf{b})$, wire-feeding rate $v_{f}$ and (c) hot-wire power $P_{\mathrm{hw}}$. Shown is the transient mean-bulk temperature in the welding zone.

In summary, the results of the numerical simulation generally confirm the results of the experimental study. In both cases, the hot-wire power has no significant effect either on the thermal management (Figures 20 and 21) or the objectives (Figure 18). A larger effect could be obtained for the pulse energy-accordingly the pulse peak power-and the wire-feeding rate on the thermal 
management and the objectives, respectively. Nonetheless, the bulk solidification times show large difference between the high-speed recordings and the numerical simulations. Whereas the bulk solidification times from the high-speed recordings vary up to about $20 \mathrm{~ms}$ from lowest to largest wire-feeding rate, the numerical simulations reveal most likely unaltered solidification times. This may be a result of the strong simplification of a solely thermal model and the disregard of geometrical changes of the weld seam with varying welding parameters, compare Figure 6.

\subsection{Hot-Cracking Susceptibility}

Based on the findings on thermal management, the correlation between welding parameters and hot-cracking can be further investigated. Figure 22 depicts the number of hot-crack defected samples (hot-cracks larger than $10 \mu \mathrm{m}$ length) of a random test of $n=4$ samples per parameter set. The left graph shows the results for pulse shape 1, the center graph shows the results for pulse shape 2 and the right graph both together. The separation of data conduces a better manageability to the reader. It is obvious, that the susceptibility to hot-cracking tends to increase with the pulse energy and pulse duration due to the higher transient thermal load in the welding zone during the laser pulse. The insufficient solidification during the pulse breaks for larger pulse energies, especially for pulse shape 2 (compare Figure 19), leads to disadvantageous temperature gradients and cooling-off of the welding zone, which negatively affects the hot-crack susceptibility. Hence shorter pulse shapes and lower pulse energies may promote sufficient solidification in the pulse breaks and reduce the hot-crack susceptibility. On the other hand, the hot-wire power does not show a systematic influence on the hot-crack susceptibility, whereas an increasing wire-feeding rate tends to reduce the susceptibility for hot-cracks. In principle, hot-cracks seam to occur primarily at high penetration depth/dilution, i.e., for large pulse energies and low wire-feeding rates (compare Figures 11 and 13). However, as this is in contradiction to increasing productivity in terms of high deposition rates and hence low dilutions, fewer hot-cracks may be expected for repair welds with possibly large buildup.
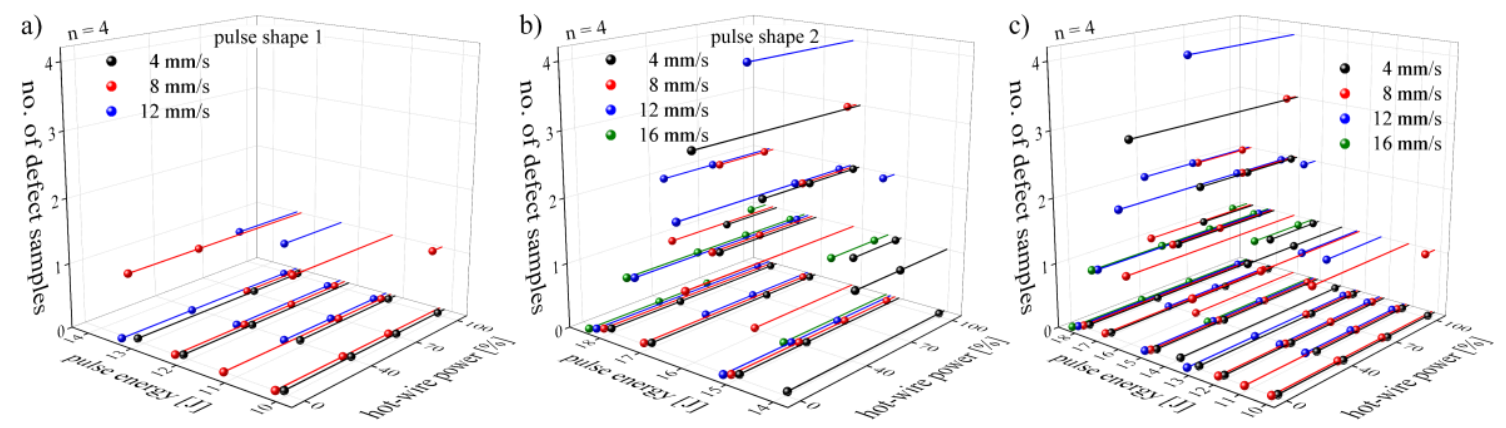

Figure 22. Number of hot-crack defected samples by random test of $n=4$ as function of pulse energy and hot-wire power for pulse shape 1 (a), pulse shape 2 (b) and both together (c).

To gain deeper insight into the hot-crack formation, a statistical analysis was also conducted. Here, no correlations could be found, which may be due to the reduced data. Hence more samples have to be investigated, especially either in cross-sections along the weld seam instead of cross-sections across the weld seam or micro-computed tomography. Thus, the probability is much larger to find, count and measure hot-cracks for increasing the significance in a statistical analysis.

\section{Conclusions}

(1) The decoupling of heat source from the laser beam into the filler material was successfully implemented by the hot-wire technology.

(2) It is demonstrated that, exceptionally, the wire-feeding rate has a significant influence on the deposition rate and hence the productivity enhancement. 
(3) The productivity could be increased up to a factor of about five compared to the initial wire-feeding rate of $4 \mathrm{~mm} / \mathrm{s}$, i.e., from initially about 4 to about $20 \mathrm{~g} / \mathrm{h}$.

(4) The hot-wire technique showed no significant influence on the melting deposition rate and the weld seam geometry as well as the hot-crack formation, i.e., the active intervention in the heat management.

(5) The largest influence on the weld seam geometry is addressed to the wire-feeding rate and the pulse energy.

(6) Increasing wire-feeding rates lead to decreasing stability of the welding process in terms of discontinuous wire-feeding.

(7) The statistical analysis revealed regression functions for predicting weld seam geometries and the associated input parameters.

(8) The hot-crack susceptibility is mainly influenced by the wire-feeding rate, pulse energy and pulse shape; the hot-wire technology is just subordinated.

(9) The hot-crack susceptibility tends to decrease for lower pulse energy, shorter pulse length and larger wire-feeding rate.

(10) Due to the limited detection of hot-cracks, a statistical analysis of the hot-crack susceptibility could not yet definitely be conducted.

Outlook:

(1) Micro-computed tomography will help to find all hot-cracks in a sample to improve the statistics and find systematic correlations between the welding parameters and the hot-crack susceptibility.

(2) The study has to be expanded to open further opportunities, e.g., base material preheating, further pulse shapes etc., for controlling the hot-crack susceptibility and intervention of the temperature-time regime as well as other material pairings and larger wire diameters.

(3) Larger diameters of the filler wire at lower wire-feeding rates may increase the melting deposition rate, pointing also to a more stable process control.

(4) Validation of the prediction model via multi-objective optimization for distinct end-use fields.

Author Contributions: Conceptualization, C.K.; methodology, C.K.; software, C.K. and M.N.; validation, C.K. and M.N.; formal analysis, C.K. and M.N.; investigation, C.K. and M.N.; resources, J.P.B.; data curation, C.K.; writing-original draft preparation, C.K.; writing-review and editing, K.S. and J.P.B.; visualization, C.K.; supervision, K.S., J.P.B.; project administration, C.K.; funding acquisition, J.P.B. All authors have read and agreed to the published version of the manuscript.

Funding: The authors acknowledge financial support of the AiF Arbeitsgemeinschaft industrieller Forschungsvereinigungen for the research project 20.023 B/DVS-No. 06.119 of the IGF Industrielle Gemeinschaftsforschung "Strategien zur Wärmeentkopplung beim gepulsten Laserstrahlauftragschweißen von Nickelbasisbauteilen zur Steigerung der Produktivität".

Conflicts of Interest: The authors declare no conflict of interests.

\section{Abbreviations}

$\begin{array}{ll}A & \text { aspect ratio } \\ A_{D} & \text { dilution area } \\ A_{H} & \text { buildup area } \\ A_{W} & \text { cross-sectional area of filler-wire } \\ D & \text { dilution } \\ \delta \tau & \text { standard deviation of bulk solidification time } \\ d_{w} & \text { diameter of filler-wire } \\ E_{L} & \text { laser pulse energy } \\ \text { exp. } & \text { experiment }\end{array}$




$\begin{array}{ll}H & \text { buildup height } \\ \text { HS 282 } & \text { Haynes 282 } \\ \text { HV } & \text { high-velocity } \\ \text { IN 738 LC } & \text { Inconel 738 low carbon } \\ l_{\text {bare }} & \text { bare wire length of Joule heating } \\ l_{\text {tip }} & \text { length of wire tip } \\ \text { n, no. } & \text { number } \\ P_{\text {laser }} & \text { laser beam power } \\ P_{\text {hww }} P_{\text {hot-wire }} & \text { hot-wire power } \\ P_{h w}^{\text {eff }} & \text { effective hot-wire power } \\ P_{h w}^{\text {max }} & \text { maximum hot-wire power } \\ P_{\text {pulse peak }} & \text { pulse peak power } \\ \text { PS } & \text { pulse shape } \\ \varphi & \text { deposition efficiency } \\ R_{d} & \text { deposition rate } \\ P_{H S 282} & \text { density of } 282 \\ \text { sim. } & \text { simulation } \\ \bar{\tau} & \text { mean value of bulk solidification time } \\ \tau & \text { bulk solidification time } \\ \Theta & \text { wetting angle } \\ T_{\text {liq }} & \text { liquidus temperature } \\ T_{\text {sol }} & \text { solidus temperature } \\ T_{\text {wire }} & \text { wire tip temperature } \\ v_{f} & \text { wire-feeding rate } \\ v_{w} & \text { weld velocity } \\ W & \text { buildup width } \\ \text { w/o } & \text { without } \\ & \end{array}$

\section{References}

1. Bürgel, R. Handbuch Hochtemperatur-Werkstofftechnik: Grundlagen, Werkstoffbeanspruchungen, Hochtemperaturlegierungen und-Beschichtungen; Springer: Berlin/Heidelberg, Germany, 2011.

2. Burbaum, B. Verfahrenstechnische Grundlagen für das Laserstrahl-Umschmelzen einkristalliner Nickelbasis-Superlegierungen. Ph.D. Thesis, Hochschulbibliothek der Rheinisch-Westfälischen Technischen Hochschule Aachen, Aachen, Germany, 2010.

3. Arjakine, N.; Piegert, S.; Slyvinskyy, O. Ni-Basis Superlegierungen im Turbomaschinenbau und deren Besonderheiten bei der schweißtechnischen Bearbeitung. In Proceedings of the 14th Sommerkurs Werkstoffe und Fügen am Institut für Werkstoff- und Fügetechnik, Magdeburg, Germany, 23-24 September 2011.

4. Denkena, B.; Boess, V.; Nespor, D.; Floeter, F.; Rust, F. Engine blade regeneration: A literature review on common technologies in terms of machining. Int. J. Adv. Manuf. Technol. 2015, 58, 917-924. [CrossRef]

5. Aschenbruck, J.; Adamczuk, R.; Seume, J. Recent Progress in Turbine Blade and Compressor Blisk Regeneration. Procedia CIRP 2014, 22, 256-262. [CrossRef]

6. Churchman, C.; Bonifaz, E.; Richards, N. Comparison of single crystal Ni based superalloy repair by gas tungsten arc and electron beam processes. Mater. Sci. Technol. 2011, 27, 811-817. [CrossRef]

7. Stimper, B. Verlängern von Verdichterschaufeln durch Laser-Pulver-Auftragschweißen. Dvs-Ber. 2000, 208, 93-97.

8. Zhang, J.; Weckmann, D.C.; Zhou, Y. Effects of Temporal pulse Shaping on Cracking Susceptibility of 6061-T6 Aluminum Nd:YAG Laser Welds. Weld. J. 2008, 87, 18-30.

9. Wilden, J.; Bergmann, J.P.; Holtz, R. Modification of solidification conditions through the set of pulsed Nd:YAG Lasers. In Proceedings of the XVI International Symposium on Gas Flow and Chemical Lasers \& High Power Lasers Conference, Gmunden, Austria, 4-8 September 2006.

10. Katayama, S.; Mizutani, M.; Matsunawa, A. Modelling of melting and solidification behaviour during laser spot welding. Sci. Technol. Weld. Join. 1997, 2, 1-9. [CrossRef] 
11. Nurminen, J.; Riihimäki, J.; Näkki, J.; Vuoristo, P. Comparison of laser cladding with powder and hot and cold wire techniques. In Proceedings of the 25th International Congress on Applications of Laser and Electro-Optics 2006, ICALEO 2006, Paper 1006, Scottsdale, AZ, USA, 30 October-2 November 2006.

12. Tsuyama, T.; Yuda, M.; Nakai, K. Effects of hot wire on mechanical properties of weld metal using gas-shielded arc welding with CO2 gas. Weld World 2014, 58, 77-83. [CrossRef]

13. Chemical composition of Inconel 738 Low Carbon. Available online: https://www.nickelinstitute.org/media/ 1709/in_738alloy_preliminarydata_497_.pdf (accessed on 27 August 2020).

14. Chemical Composition of Haynes 282. Available online: http://haynesintl.com/docs/default-source/pdfs/newalloy-brochures/high-temperature-alloys/brochures/282-brochure.pdf?sfvrsn=20 (accessed on 27 August 2020).

15. Bergmann, J.P.; Bielenin, M. Prozessstrategie zum Reparieren von Nickelbasisbauteilen mittels Laserstrahl; AIF-Abschlussbericht-IGF-Nr. 18334/BR1; DVS Research Association: Düsseldorf, Germany, 2017.

16. Kästner, C.; Schmidt, L.; Leinhoß, R.; Behr, A.; Schricker, K.; Bergmann, J.P. Produktivitätssteigerung Beim Gepulsten Laserstrahl-Auftragschweissen Von Nickelbasis-Superlegierungen Durch Entkopplung Der Wärmeanteile. In Proceedings of the 11th Mittweidaer Lasertagung, Mittweida, Germany, 13-14 November 2019; pp. 3-8.

17. Stritt, P. Prozessstrategie zur Vermeidung von Heißrissen beim Remote-Laserstrahlschweißen von AlMgSi 6016. Ph.D. Thesis, Universität Stuttgart, Stuttgart, Germany, 2016.

18. Bielenin, M.; Sieber, P.; Bergmann, J.P. Neuer Ansatz für die Reparatur von Ni-Basisbauteilen mit Gepulstem Laserstrahl und Drahtförmigen Zusatzwerkstoffen. In Proceedings of the DVS Congress 2015, Nuremberg, Germany, 14-17 September 2015; pp. 381-386.

19. Keller, B.P.; Nelson, S.E.; Walton, K.L.; Ghosh, T.K.; Tompson, R.V.; Loyalka, S.K. Total hemispherical emissivity of Inconel 718. Nucl. Eng. Des. 2015, 287, 11-18. [CrossRef]

20. Kieruj, P.; Przestacki, D.; Chwalczuk, T. Determination of emissivity coefficient of heat-resistant super alloys and cemented carbide. Arch. Mech. Technol. Mater. 2016, 36, 30-34. [CrossRef]

21. Kirchhoff, G. Ueber das Verhältniss zwischen dem Emissionsvermögen und dem Absorptionsvermögen der Körper für Wärme und Licht. Ann. Der Phys. Und Chem. 1860, 109, 275-301. [CrossRef]

22. Aune, R.E.; Battezzati, L.; Brooks, R.; Egry, I.; Fecht, H.J.; Garandet, J.P.; Hayashi, M.; Mills, K.C.; Passerone, A.; Quested, P.N.; et al. Thermophysical properties of IN738LC, MM247LC and CMSX-4 in the liquid and high temperature solid phase. Superalloys 2005, 718, 625-706.

23. Günther, K. Werkstofftechnische Betrachtung zum Heißdraht unterstützten MSG-Auftragschweißen hartstoffverstärkter Verschleißschutzlegierungen. Ph.D. Thesis, Universitätsverlag Ilmenau, Ilmenau, Germany, 2017.

24. Meyer, R.; Krueger, D. MINITAB Guide to Statistics, 2nd ed.; Prentice Hall PTR: Upper Saddle River, NJ, USA, 2001.

25. Anderson, T.W.; Darling, D.A. Asymptotic Theory of Certain "Goodness of Fit" Criteria Based on Stochastic Processes. Ann. Math. Stat. 1952, 23, 193-212. [CrossRef]

26. Box, G.E.P.; Wilson, K.B. On the experimental attainment of optimum conditions. J. R. Stat. Soc. Ser. B (Methodological) 1951, 13, 1-38. [CrossRef]

27. Box, G.E.P.; Cox, D.R. An analysis of transformations. J. R. Stat. Soc. Ser. B (Methodological) 1964, 26, $211-252$. [CrossRef]

28. Kästner, C.; Neugebauer, M.; Schricker, K.; Bergmann, J.P. Statistical analysis of pulsed laser beam welding repair strategies of Nickel-base superalloys. Procedia CIRP 2020, in press.

(C) 2020 by the authors. Licensee MDPI, Basel, Switzerland. This article is an open access article distributed under the terms and conditions of the Creative Commons Attribution (CC BY) license (http://creativecommons.org/licenses/by/4.0/). 